\title{
Developmental Kinetics of GAD Family mRNAs Parallel Neurogenesis in the Rat Spinal Cord
}

\author{
Roland Somogyi, Xiling Wen, Wu Ma, and Jeffery L. Barker \\ Laboratory of Neurophysiology, NINDS, NIH, Bethesda, Maryland 20892
}

GABA ( $\gamma$-amino butyric acid), a fast-acting synaptic transmitter in the mature CNS, is synthesized from glutamate by GAD (glutamic acid decarboxylase). We have developed an ultrasensitive PCR technique to quantify the expression of GAD-related mRNAs during the development of the rat cervical spinal cord and have localized them using in situ hybridization. GAD65, GAD67, and an alternatively spliced variant of GAD67, EP10, were quantified each day from embryonic (E) day 11 through E21, and at postnatal days 0, 7, 14, and adult. GAD65 and GAD67 mRNAs were detected at E11 and increased exponentially over three orders of magnitude during embryonic development, then declined approximately threefold In the first 2 postnatal weeks. While the exponential growth phase coincided with the progressive appearance of GAD67 in situ signals in both the ventral and dorsal cord, the postnatal decline coincided with the virtual disappearance of expression in the ventral region. EP10 expression was prominent in the embryo, then declined markedly together with the mRNA encoding the neuroepithelial stem cell marker, nestin. The concerted appearance of GAD-related mRNAs paralleled transcripts encoding neuronal markers (light and heavy neurofilaments) and also closely correlated with the expression of GABA, mRNAs encoding GABA $_{A}$ receptor subunits, and depolarizing responses to GABA. We have used the results on GAD-related mRNA expressions to formulate a simple, minimal mathematical model that accounts for their kinetics in terms of positive and negative feedback loops.

[Key words: GAD, ontogeny, neurogenesis, alternative splicing, rat, spinal cord, quantitative PCR, mathematical model]

For simplicity, CNS development can be summarized as the.concerted differentiation of complex gene expression patterns as the tissue transforms from a proliferative mode into functional networks and systems of fast-transmitting circuits. Recent studies on the ontogeny of neurotransmitter systems have led to the conclusion that transmitters mediate cues and signals that, in turn, regulate the expression of genes during critical periods (reviewed in Spitzer, 1991; Lauder, 1993). We have focused on the role of $\gamma$ - amino butyric acid (GABA) as a morphogenic signal

\footnotetext{
Received Aug. 24, 1994; revised Oct. 12, 1994; accepted Oct. 18, 1994.

We thank Gabor Szabo for helpful discussions and a preprint of work detailing the alternative splicing products of GAD67, Ze'ev Silverman for critical discussions on the manuscript, and K. M. Tang for help with the tissue dissections.

Correspondence should be addressed to Roland Somogyi, Ph.D., Laboratory of Neurophysiology, NIH/NINDS, Building 36/2C02, Bethesda, MD 20892.

Copyright (C) 1995 Society for Neuroscience $0270-6474 / 95 / 152575-17 \$ 05.00 / 0$
}

in CNS development. GABA is well established as a fast-acting neurotransmitter in the well-differentiated CNS, primarily mediating signals that briefly alter or inhibit electrical excitability (Sivilotti and Nistri, 1991). Recently, GABA was demonstrated in the early developing CNS, where it is thought to play important roles in CNS differentiation (Lauder et al., 1986; Redburn and Schousboe, 1987; Spoerri, 1988; Wu et al., 1992).

The major pathway for GABA synthesis is enzymatic decarboxylation of glutamate by glutamic acid decarboxylase (GAD). The importance of GAD in CNS development is emphasized by its early phylogenetic origin; the gene has now been cloned from a simple eukaryotic organism, Neurospora crassa, where its expression parallels conidiation, that is, developmental metamorphosis (Hao and Schmit, 1993). In the rat, two isoforms of GAD (GAD65 and GAD67) have been identified; GAD65 and GAD67 share $70 \%$ sequence homology and originate from two chromosomes (Erlander et al., 1991; reviewed in Erlander and Tobin, 1991). The two enzymes differ in their cofactor requirements and subcellular localizations (Erlander and Tobin, 1991). GAD65 is largely membrane bound and relatively enriched in vesicular membranes, while GAD67 is soluble and distributed in the cytoplasm. GAD65 is thought to be more critical in the production of GABA for synaptic transmission of GABAergic signals. Furthermore, GAD67 mRNA exists as at least three alternatively spliced transcripts (Bond et al., 1990), two of which are characterized by insertions of $80 \mathrm{bp}$ (EP10) and $86 \mathrm{bp}$ (E15PCR), respectively. E15PCR and EP10 both code for a short, enzymatically inactive GAD fragment, while translation of EP10 produces an additional protein possessing GAD activity (Szabo et al., 1994). The additional exons of EP10 and E15PCR contain stop codons in the GAD reading frames, resulting in a dysfunctional, truncated GAD protein. However, in the EP10 transcript, the stop codon is immediately followed by a start codon, leading to the translation of the enzymatically active portion of the GAD protein lacking the $\mathrm{NH}_{2}$-terminal amino acids. Although this start codon is also present in the E15PCR transcript, the additional, downstream 6 bp insertion contains a further in-frame stop codon, prematurely terminating translation of the functional region of GAD.

Although GAD is expressed during early CNS development, previous studies have focused primarily on its postnatal expression (Greif et al., 1991, 1992; Willcutts and Morrison-Bogorad, 1991), thereby excluding the most prolific period of neurogenesis, which occurs before birth. In the rat spinal cord, immunocytochemical data suggest that GAD expression changes dramatically during development, beginning in the embryonic period (Ma et al., 1992; Behar et al., 1993a). Nevertheless, a definitive account of the developmental expression of GAD calls 
Table 1. Sequences of PCR primers and in situ hybridization probe

\begin{tabular}{lcll} 
Probe & $\begin{array}{l}\text { ORF } \\
\text { position }\end{array}$ & Length & Sequence \\
\hline PAW108f3 & 319 & 22 & 5'-CCAGC CATCC TTCGA GATTT CT-3' \\
PAW108r1 & 444 & 25 & 5'-GTTGT TCCTC CAGTT CTTTC TCACC-3' \\
GAD65f & 13 & 21 & 5'-GGCTC TGGCT TTTGG TCCTT C-3' \\
GAD65r & 426 & 25 & 5'-TGCCA ATTCC CAATT ATACT CTTGA-3' \\
GAD67f & 438 & 23 & 5'-GCTGG AAGGC ATGGA AGGTT TTA-3' \\
GAD67r & 713 & 28 & 5'-AATAT CCCAT CACCA TCTTT ATTTG ACC-3' \\
EP10r & 662 & 20 & 5'-TGAGC CCCAT CACCG TAGCA-3' \\
Nestinf & 539 & 23 & 5'-GGAGG ACCAG AGGAT TGTGA ACC-3' \\
Nestinr & 865 & 23 & 5'-ACTGC CATCT GCTCA TTCCC TAC-3' \\
NFMf & 1412 & 21 & 5'-GAAAT GGAAG ACGCC CTCAC A-3' \\
NFMr & 1852 & 21 & 5'-GGCTT TGGCT TCTGG TTTG G-3' \\
NFLf & 170 & 20 & 5'-ACCTC TCCGC CGCTC TCAAG-3' \\
NFLr & 758 & 23 & 5'-TCTCC TCCAC CTCTG ACTGC TCC-3' \\
GAD65 in situ & 1298 & 48 & 5'-GGCGT CCACA CTGCA AGGCC TTGTC TCCCG TGTCA TAGGA CAGGT CAT-3' \\
GAD67 in situ & 14 & 48 & 5'-TAGTA TTAGG ATCCG CTCCC GCGTT CGAGG AGGTT GCAGG CGAAG GCG-3'
\end{tabular}

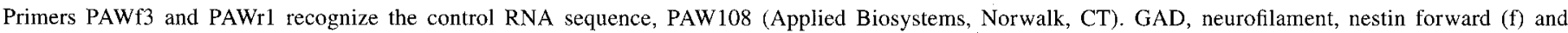

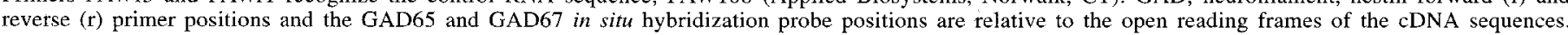

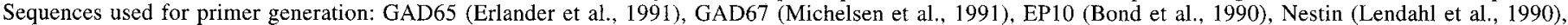
NFM (Napolitano et al., 1987), NFL (Julien et al., 1985).

for a detailed study of the abundance of mRNA molecules coding for all members of the GAD family.

We investigated the expressions of GAD family mRNAs in the developing cervical spinal cord using hot-start quantitative reverse transcription PCR (QRTPCR). The exceptional sensitivity and precision of this method allowed us to construct a highresolution calendar of GAD expression from early embryonic development to adulthood. The results demonstrate that GAD transcript upregulation closely parallels the period of both neurogenesis and the cellular expression of other functional components of the embryonic GABA signaling system. Furthermore, the quantitative account of transcript abundance has enabled us to formulate a minimal model of GAD regulation that involves both positive and negative feedback components. This model serves as a working hypothesis to interpret the accumulated data and to provide testable predictions that will help elucidate the mechanisms by which GAD gene expression is regulated.

\section{Materials and Methods}

lissue and RNA sample preparation. The cervical regions of spinal cords were quickly dissected from embryonic, postnatal, and adult rats (Taconic Farms, Germantown, NY). Rats were sacrificed according to NIH animal welfare guidelines. Embryonic age was determined by measuring crown rump length. Dissections were performed under a stereomicroscope microscope. Meningeal tissues and dorsal ront ganglia were eliminated. Tissue samples were pooled from one or two litters, depending on the age of the embryos. Total RNA was isolated according to a procedure based upon Chomczynski and Sacchi (1987). Briefly, $50-100 \mathrm{mg}$ of tissue were triturated in $1 \mathrm{ml}$ of RNA isolation reagent, RNAstat 60 (Tel-Test, Inc., Friendswood, TX), then mixed with $200 \mu l$ of chloroform per $1 \mathrm{ml}$ of honogenate. After 15 min centrifugation at $4^{\circ} \mathrm{C}$ at $12,000 \times g$, the upper aqueous layer was removed. The RNA was precipitated in 1 vol of isopropanol overnight. Following centrifugation, the RNA pellet was washed and centrifuged in $75 \%$ ethanol and dried for $10 \mathrm{~min}$ at room temperature. The partially dried RNA was taken up in DEPC-treated $\mathrm{H}_{2} \mathrm{O}$ and adjusted to $100 \mathrm{ng} / \mu \mathrm{l}$. To confirm purity of the RNA, absorption ratios at $260 \mathrm{~nm} / 280 \mathrm{~nm}$ were determined to be $>1.8$ for all samples.

Primer design. The primers for GAD, nestin, neurofilament mRNAs, and the PAW108 control RNA (Applied Biosystems, Foster City, CA) were designed using the OLIGo 4.0 software (National Biosciences,
Plymouth, MN). Primer design was optimized with regard to a standardized melting temperature $\left(\sim 60^{\circ} \mathrm{C}\right)$, primer dimer formation, internal hairpin loops and false priming sites within the target and the related sequences. The open reading frames of the genes were used for primer generation. Primer sequences are listed in Table 1.

Restriction digestion. To confirm the sequence identity of the PCR products, restriction sites were found that predict individually specific fragment sizes after digestion of each product. The restriction endonuclease recognition sites and results of the restriction digestion are shown in Figure 1. The reaction contained $15 \mu \mathrm{l}$ of PCR product mixed with $2 \mu \mathrm{l}$ of $10 \times$ reaction buffer, $2 \mu \mathrm{l}$ of $10 \times$ BSA solution, and $1 \mu \mathrm{l}$ of $10 \times$ restriction endonuclease, as provided by the supplier (New England Biolabs, Boston, MA). The digestion mixture was incubated for $2 \mathrm{hr}$ at $37^{\circ} \mathrm{C}$. Restriction products were displayed on ethidium bromidestained polyacrylamide gels.

RNase treatment. RNA samples may contain DNA contaminations, which could result in non-RNA-derived reaction products. To control for this source of artifact, some RTPCR reactions were carried out without reverse transcriptase. Since Taq polymerase contains reverse transcriptase activity, a reaction in which the reverse transcription step has been omitted may still produce RNA-derived PCR products. Therefore, we pretreated RNA samples with DNase-free RNase 1 (Promega, Madison, WI), which were then tested for contaminating DNA serving as a reaction template. Additional RNA samples were prepared for reverse transcription as above for the control experiment, while reverse transcriptase and RNase inhibitor were omitted for the test. One of the test samples was pretreated with $20 \mathrm{U}$ of RNase $1 / 200 \mathrm{ng}$ RNA in a $20 \mu \mathrm{l}$ volume for $1 \mathrm{hr}$. The protocol for RTPCR was then completed as above.

Hot-start quantitative RTPCR. We used the hot-start PCR technique to optimize fidelity in the multiplex, quantitative RTPCR reaction using two templates and two primer sets. RTPCR was performed in a Perkin Elmer 9600 Thermal Cycler using the Perkin Elmer GeneAmp RNA PCR kit (Applied Biosystems) according to the recommended protocol. Total sample RNA (80 ng) and 80 copies of control RNA (PAW108, Applied Biosystems) were combined for each final $40 \mu$ l RTPCR reaction. Reverse transcriptions at one-fifth of final PCR reaction volume were pooled for later amplification by different primers. Control RNA from one lot was diluted to a 100 molecule/ $\mu$ l stock, then aliquoted and frozen at $-70^{\circ} \mathrm{C}$ to assure reproducibility of control template. Reverse transcription, using the furnished random hexamer primers, was carried out for $45 \mathrm{~min}$ at $42^{\circ} \mathrm{C}$, preceded by a $10 \mathrm{~min}$ incubation at room temperature for primer annealing, followed by $5 \mathrm{~min}$ at $95^{\circ} \mathrm{C}$ for inactivation of reverse transcriptase. Primers, cDNA, and PCR components, except for a $10 \mu \mathrm{l}$ volume containing Taq polymerase and $\mathrm{H}_{2} \mathrm{O}$, were pipetted into a $100 \mu \mathrm{l}$ reaction tube and placed in the thermal cycler 
a

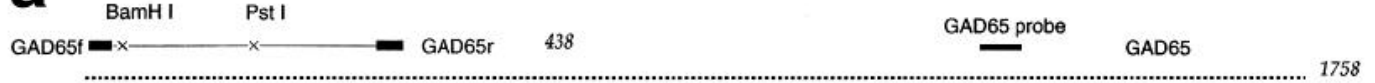

\begin{tabular}{|c|c|c|c|}
\hline 67 probe & EcoR V & & \\
\hline & GAD67i $=$ & 303 & GAD67 \\
\hline
\end{tabular}

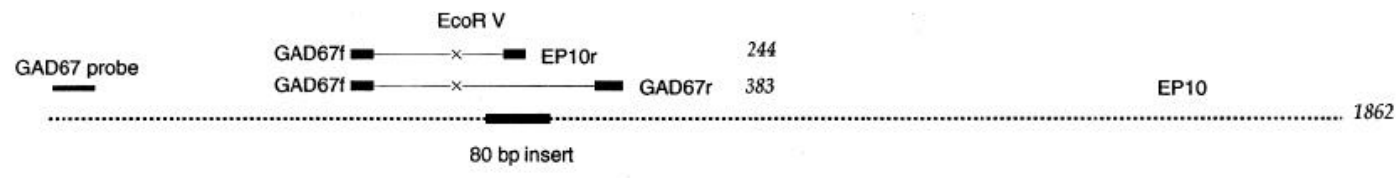

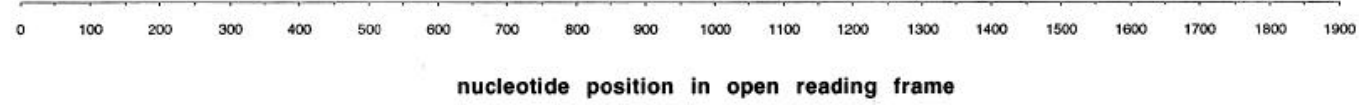
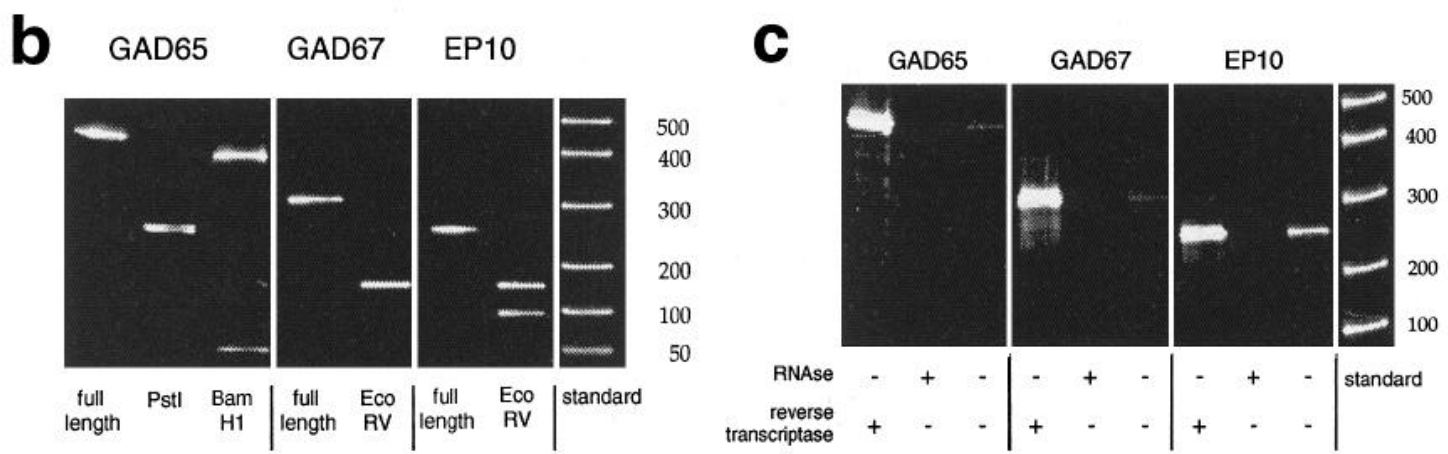

Figure 1. Design and fidelity of GAD family mRNA detection. a, Positions of PCR primers, amplification products and in situ hybridization probe on GAD open reading frames. Bold lines flanking PCR products (thin lines) depict exact primer and in situ probe lengths and positions (also see Table 1). Restriction endonuclease cutting sites are marked by $x$. GAD67f, GAD67r primers, and the GAD67 in situ probe also recognize EP10. The resulting PCR product for EP10 is extended by 80 bp. The EP10r primer is targeted to the 80 bp insert of EP10 (bold line in EP10 sequence), enabling specific recognition of EP10. Sequence and PCR product lengths are shown in italics. $b$, Restriction analysis. GAD65 (438 bp) digestion is predicted to produce fragment pairs of lengths $208 \mathrm{bp} / 230 \mathrm{bp}$ for PstI, and $43 \mathrm{bp} / 395 \mathrm{bp}$ for BamHI. PCR products for GAD67 (303 bp) and EP10 (244 bp; using EP10r reverse primer) have EcoRV recognition sites, resulting in product pairs of $149 \mathrm{bp} / 154 \mathrm{bp}$, and $149 / 95 \mathrm{bp}$, respectively. The closely appositioned 149 bp and 154 bp bands for GAD67 cannot be separated due to the limited resolution of the gel. $c$, RNA template identity. RNA sample (adult rat cervical spinal cord total RNA) was pretreated with RNAse 1 to eliminate template for the reverse transcriptase activity of Taq polymerase. It was amplified using the same RTPCR protocol as for the control, except for omission of reverse transcriptase. This and another sample, which neither contained reverse transcriptase, nor was pretreated with RNAse, were compared to the control.

block. Following preheating to $95^{\circ} \mathrm{C}$ for $30 \mathrm{sec}$, the reaction was cooled to $60^{\circ} \mathrm{C}$ and the final $10 \mu \mathrm{l}$ of reaction mix were added to each tube. The amplification protocol then began with a 2 min preincubation at $95^{\circ} \mathrm{C}$, followed by 35 cycles of $30 \mathrm{sec}$ at $95^{\circ} \mathrm{C}$ (dissociation), $30 \mathrm{sec}$ at $60^{\circ} \mathrm{C}$ (primer annealing), and $30 \mathrm{sec}$ at $72^{\circ} \mathrm{C}$ (extension), and completed by a $7 \mathrm{~min}$ incubation at $72^{\circ} \mathrm{C}$ to complete primer extension. The PCR reaction mixture contained $2 \mathrm{mM} \mathrm{MgCl}_{2}$ and the other components at the prescribed concentrations.

PCR product detection. PCR products were separated on 10-well 8 $16 \%$ polyacrylamide gradient gels (Novex, San Diego, CA), using BioMarker low DNA size standards (Bio Ventures, Murfreesboro, TN) as a reference. Gels were stained for $30 \mathrm{~min}$ with $0.1 \%$ ethidium bromide solution, illuminated on a UV transilluminator, and documented with black and white instant film. For quantification of band intensities, black and white images were scanned at 300 dots per inch using a 256 bit grayscale and analyzed with the IMAGE software (Wayne Rasband, RSB, NIMH, NIH, Bethesda, MD) on a Macintosh Quadra $650 \mathrm{com}-$ puter. Densitometry was carried out using the gel analysis macro of IMAGE.

Calibration of quantitative RTPCR. Sample template DNA was isolated from RTPCR reactions and agarose gel purified. We prepared dilution series from an adjusted stock, following spectrophotometric concentration determination using calculated molar extinction coefficients at $260 \mathrm{~nm}$ (OLIGo 4.0 software, National Biosciences, Plymouth, MN). Known numbers of molecules $\left(10-10^{8}\right)$, shown with respect to the 10 $\mu l$ reaction volume loaded on the gel (Fig. 2), were introduced into calibration reactions. The results were averaged from triplicate reac- tions, and used to plot and linearly fit the calibration curves (see Results).

In situ hybridization. For preparation of in situ hybridization tissue, the pregnant rats were taken at different gestational days and were anesthetized with chloral hydrate $(400 \mathrm{mg} / \mathrm{kg}$, i.p.). Embryos were removed from the uterus by cesarean section, and whole bodies were immediately frozen on dry ice. Young postnatal rats (P0, P7, P14) were anesthetized by hypothermia and the spinal cords were dissected and quickly frozen on dry ice. Adult rats were anesthetized with chloral hydrate $(400$ $\mathrm{mg} / \mathrm{kg}$ ), and the spinal cords dissected and freshly frozen. Coronal sections ( $12 \mu \mathrm{m}$ thick) through the spinal cord were cut on a cryostat, thaw mounted onto gelatin-coated slides, and stored at $-70^{\circ} \mathrm{C}$ until use.

The GAD67 and GAD65 probes (see Table 1 for sequences) were labeled with ${ }^{35}$ S-dATP (3500-5000 Ci/mm; New England Nuclear, Boston, MA) by terminal deoxynucleotidyl transferase (Boehringer-Mannheim, Indianapolis, IN). The labeled oligomers were separated from the enzyme and unincorporated ${ }^{35} \mathrm{~S}$-dATP residues with Select-D Sephadex G-25 spin columns $\left(5^{\prime}-3^{\prime}\right.$; Boulder, $\left.\mathrm{CO}\right)$.

Sections were processed for in situ hybridization as described previously (Ma et al., 1993). Briefly, the sections were fixed in 4\% paraformaldehyde in $0.1 \mathrm{M}$ phosphate buffer $(\mathrm{pH} 7.3)$ for $5 \mathrm{~min}$, rinsed twice in PBS, and acetylated with $0.25 \%$ acetic anhydride in $0.1 \mathrm{M}$ triethanolamine $\mathrm{HCl} / 0.9 \% \mathrm{NaCl}$ for $10 \mathrm{~min}$. After this, they were dehydrated through a graded series of ethanol solutions, delipidated in chloroform, rehydrated, and air dried. The sections were then hybridized overnight at $37^{\circ} \mathrm{C}$ with one of the labeled probes dissolved in hybridization buffer at a concentration of 1-2 $\times 10^{6} \mathrm{dpm} / 50 \mu \mathrm{l}$. Hybridization buffer con- 
a

GAD 65

Figure 2. Quantitative hot-start RTPCR calibration and data analysis. $a$, Ethidium bromide-stained polyacrylamide gels of calibration reactions. The top series of bands result from the amplification of shown numbers of starting molecules (per $10 \mu \mathrm{l}$ reaction volume) of GAD65, GAD67, and EP10 RT-PCR product (top to bottom gels, respectively). Templates were reverse transcribed and coamplified with a constant amount of control RNA, which produced the lower series of bands (149 bp). b, Analysis of digital gel images. Top, Density histogram of the GAD65 calibration gel shown in $a$. The integrated relative area is shown above each peak; corresponding logarithms of number of starting molecules and of the template/control area ratio are listed below. Bottom panel, Graphic representation of $\log N(N=$ starting template molecules) and $\log R[R=$ (template area)/(control area)]. $c$, Calibration of quantitative RT-PCR. The calibration curves show the averages and standard deviation bars of three independent determinations of $\log R$ versus $\log N$ for each template. The data were fitted linearly, resulting in the shown regression lines. Fitting parameters $(\log R=m \cdot \log N+b)$ : GAD65, $m=0.36 ; b=-1.09 ; R=$ 0.99. $G A D 67, m=0.29 ; b=-0.87$ $R=0.98 . E P 10, m=0.33 ; b=-0.67$; $R=0.93$.

C
Log no. of starting molecules:
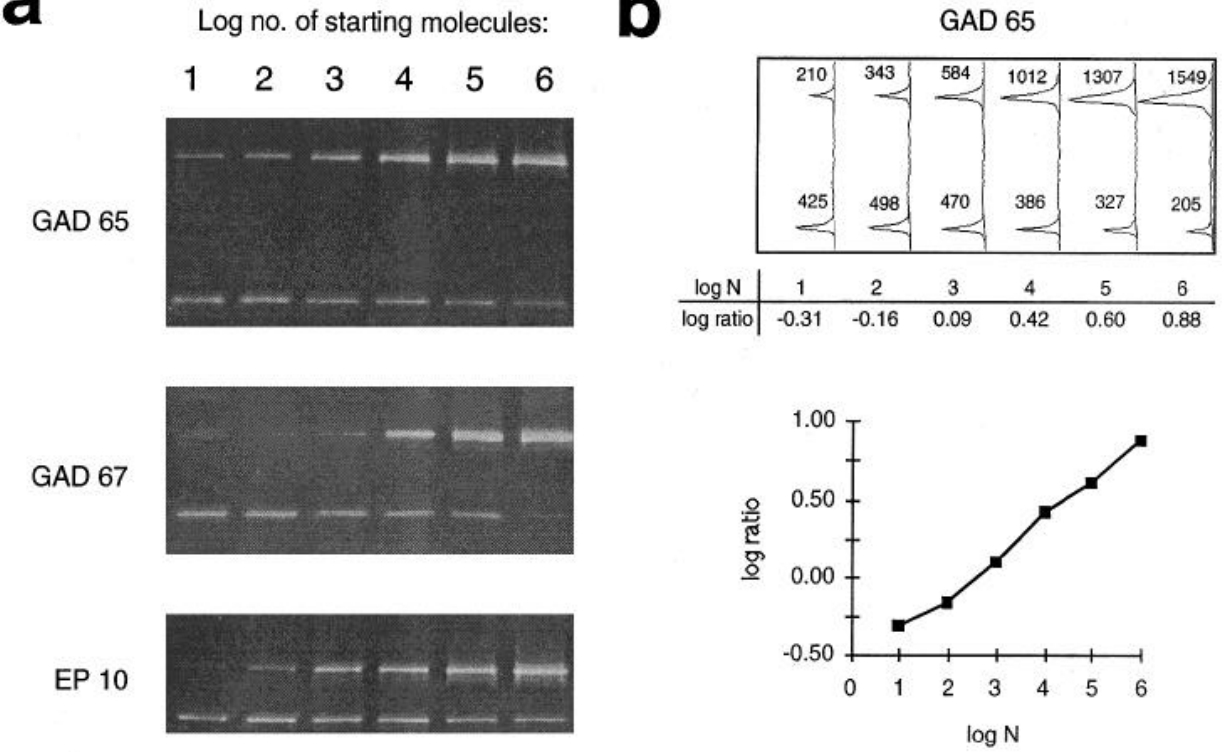
GAD 65 GAD 67 EP 10
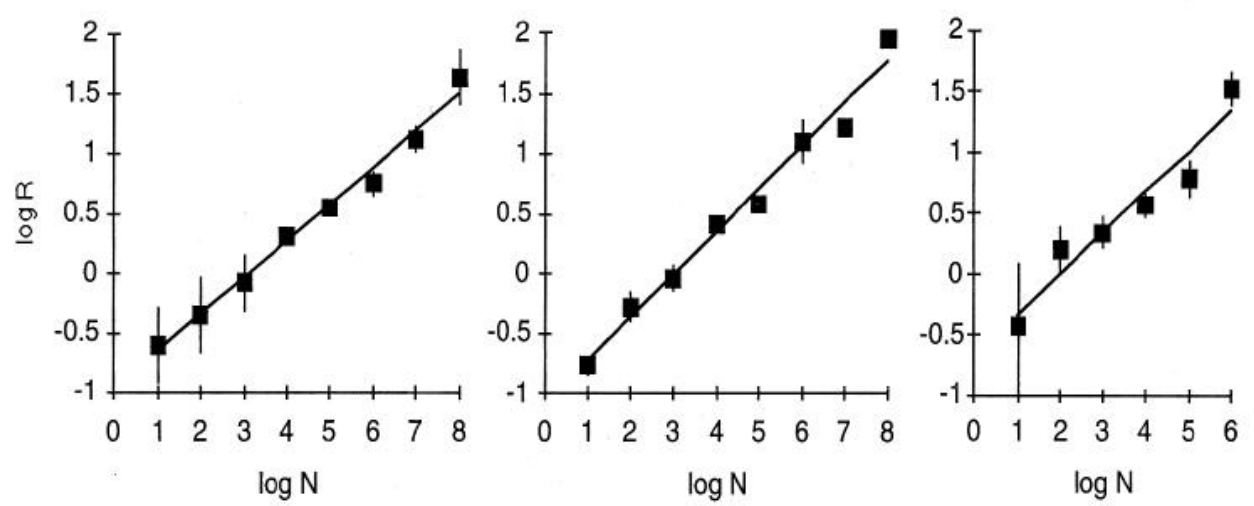

tained $4 \times$ standard saline solution (SSC), $50 \%$ formamide, $10 \%$ dextran sulfate, and $10 \mathrm{~mm}$ dithiothreitol. Sections were washed in $1 \times \mathrm{SSC}$ for $15 \mathrm{~min}$ four times at $55^{\circ} \mathrm{C}$, and then washed $2 \times$ in $1 \times \mathrm{SSC}$ for $1 \mathrm{hr}$ at room temperature. Sections were rinsed in distilled water and dried.

The hybridized sections were exposed on $\beta$ max-Hyperfilm (Amersham, Arlington Heights, IL) for 3 weeks at room temperature. The specificity of hybridization was assessed by (1) pretreatment of selective sections with ribonuclease A $(100 \mu \mathrm{g} / \mathrm{ml})$ prior to hybridization and (2) incubation with hybridization solution without labeled probe. These treated sections were washed and exposed in the same experiments as the probed tissues. No detectable signal was found above background level in any of these sections.

\section{Results}

\section{Quantitative hot-start RTPCR of GAD family transcripts}

Unequivocal identification of GAD family transcripts by RTPCR.

The data presented here were collected from at least triplicate experiments carried out on more than 135 independent dissections of cord tissues. GAD65, GAD67, and EP10 primers (Table 1) were designed within the open reading frames of the corresponding cDNAs (Erlander et al., 1991; Michelsen et al., 1991) to yield PCR products of $438 \mathrm{bp}, 303 \mathrm{bp}$, and $244 \mathrm{bp}$, respectively (Fig. 1). Since EP10 and E15PCR, the alternatively spliced products of the GAD67 gene, respectively, contain an
80 bp and 86 bp insert (Bond et al., 1990), both sequences provide additional priming sites. They were jointly amplified with a reverse primer, EP10r (Table 1), targeted to the insert, in combination with the standard GAD67f primer (Fig. 1). The 80 bp insert of EP10 is contained within the 86 bp sequence of E15PCR. However, we did not selectively target the 6 bp insertion specific for E15PCR because of concerns about PCR priming fidelity. Therefore, we will subsequently refer to the extended transcripts as EP10. The amplified PCR products correspond to the predicted positions with respect to the size standards (Fig. $1 b, c)$.

The reverse transcription polymerase chain reaction (RTPCR) is the most sensitive method to detect mRNA (reviewed by Arnheim, 1992). We used the technique of hot-start PCR (Chou et al., 1992) to avert formation of mispriming artifacts. To verify sequence identity of the PCR products with respect to the parent gene, we performed endonuclease digestions for each product (Fig. 1a). Cleavage of GAD65 product resulted in the predicted expected bands for PstI and BamH1 (Fig. 1b). EcoRV digestion of the GAD67 product yielded a band in the mapped position containing both restriction fragments of approximately equal expected length (Fig. 1b). Cutting the EP10 product by EcoRV 

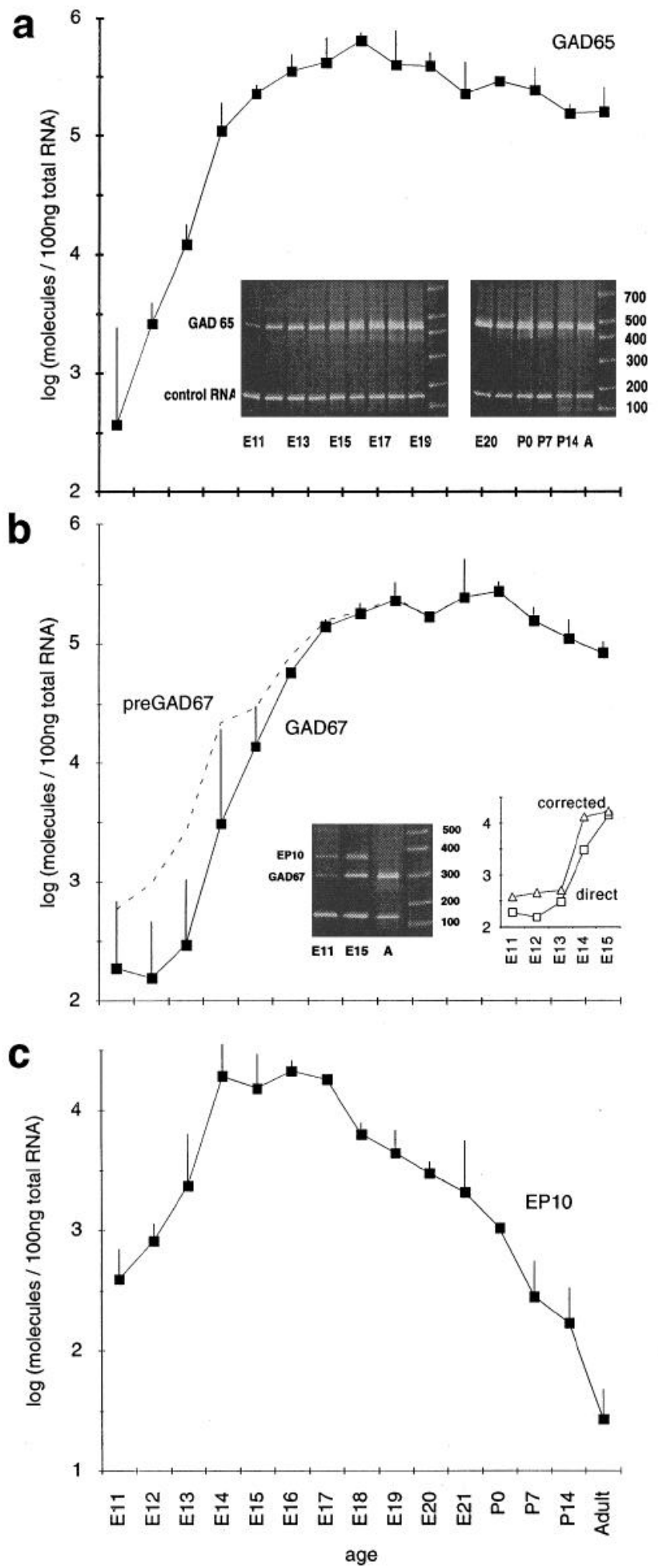

Figure 3. GAD family mRNA expression in rat cervical spinal cord from E11-adult. Total RNA samples and control RNA were coamplified using quantitative hot-start RTPCR to yield the GAD family and control RNA products. Data from triplicate tissue preparations were pooled and used to determine the numbers of template molecules per $100 \mathrm{ng}$ total RNA (see text and Fig. 2). The graphs show the averages and standard deviations over daily intervals during the embryonic period, and weekly intervals for postnatal development $(\mathrm{P0}=\mathrm{E} 22$, Adult $=\mathrm{P} 90)$. $a$, Developmental profile of GAD65 mRNA abundance. GAD65 transcripts were detected at E11 (670 molecules/100 ng RNA), reached a maximum produced the same band as with GAD67, and an additional, lower molecular weight band (Fig. 1b), as expected for the truncated sequence flanked by the GAD67f and EP10r primers (Fig. 1a).

To determine if DNA-based PCR products were generated from our tissue RNA samples, the PCR was performed directly on nonreverse transcribed RNA, ostensibly amplifying only contaminating DNA (Liang et al., 1993). However, since Taq polymerase also exhibits reverse transcriptase activity (Jones and Foulkes, 1989; Tse and Forget, 1990), RNA was eliminated prior to testing by RNAse 1 (Promega, Madison, WI) digestion of the sample and subsequently compared to a control sample and another, non-RNAse-treated test sample. No PCR product was detected in the RNAse-treated samples for GAD65, GAD67, EP10, and control RNA (Fig. $1 c$; control RNA not shown), eliminating DNA as a template source.

Wide dynamic range of quantitative RTPCR for GAD family transcripts. Several approaches have been described in the design of quantitative RTPCR protocols (reviewed by Siebert and Larrick, 1992; Foley et al., 1993). Reproducible extrapolation to the amount of original template from PCR-amplified DNA required introduction of a control RNA as an internal standard for all reaction steps. We used an artificial RNA (see Materials and Methods), which we independently primed, resulting in a 149 bp product (inset, Fig. $3 a$ ). Using hot-start PCR, control RNA and sample primers could be combined in a single reaction while minimizing artifacts due to primer-primer interactions (Figs. 2, 3). We measured the sensitivity and dynamic range of the quantitative RTPCR protocol, and found clear and consistent changes in band intensity for 10 to $1,000,000$ starting molecules of GAD65, GAD67, and EP10 templates. Sample: control ratios were determined from integrated peak pixel areas corresponding to the individual band intensities (top, Fig. $2 a, b$ ). The logarithm of the number of starting molecules, $N$, was linearly related to the logarithm of the sample: control ratio (Fig. $2 b$, bottom). This relationship demonstrates that the control RNA serves as a dependable internal standard, even though it is not a strict competitor that shares the template primers.

Calibration curves were well fitted according to $\log r=$ $m \cdot \log N+b$. The fitting parameter values for GAD65, GAD67, and EP10, respectively, corresponded to $0.36,0.29$, and 0.33 for $m, 1.09,0.87$, and 0.67 for $b$, and $0.99,0.98$, and 0.93 for $R$, the correlation coefficient. The modest range in these values showed that the reaction characteristics do not vary greatly for each template. The number of starting mRNA molecules in the tissue RNA samples, $N_{\text {mRNA }}$, was calculated according to log-

$\leftarrow$

at E18 (638,000), and leveled off in the adult $(159,000)$. The inset shows an ethidium bromide-stained polyacrylamide gel from a typical experimental series (GAD65, 438 bp; control RNA, 149 bp). b, Developmental profile of GAD67 mRNA abundance. GAD67 transcripts were detected at E11 (190), reached a maximum at P0 $(275,000)$, and leveled off in the adult $(83,176)$. Amplification of embryonic total RNA with the GAD67f and GAD67r primers yielded both the GAD67 (303 bp) and EP10 (383 bp) PCR products (left inset). The right inset shows a corrected calculation to compensate for competition by EP10. The corrected values (triangles), calculated according to GAD67 [corrected] $=$ GAD67/EP10 [determination here] * EP10 [independent determination], panel $c$, do not greatly differ from the directly calculated values (squares). The direct calculation is therefore shown in the main graph. $c$, Developmental profile of EP10 mRNA abundance. EP10 transcripts were detected at E11 (390), reached a maximum at E18 (21,400), and leveled off in the adult (27). 
$N_{\text {ItRNA }}=\log 2+\log R / m-b$. For GAD65 and GAD67, the dynamic range of the RTPCR spanned 8 orders of magnitude (Fig. $2 c$ ). EP10 mRNA, which did not reach the same expression level (Fig. 3c), was calibrated over 6 orders of magnitude (Fig. $2 c$ ). Thus, this quantitative hot-start RTPCR protocol exhibited a wide dynamic range, allowing measurement of $10^{1}$ to $10^{8}$ template molecules per $10 \mathrm{ng}$ of total RNA in a $10 \mu \mathrm{l}$ PCR reaction. All potential experimental errors are taken into account in the highly reproducible and sensitive calibration curves, serving as a dependable basis for quantitation.

\section{Transient $G A D$ family $m R N A$ abundance during development}

Figure 3 details the time course of GAD family transcript expression during embryonic and postnatal development of the rat cervical spinal cord. The results of a typical experiment are shown in the inset of Figure $3 a$ for GAD65. GAD65 mRNA was readily detected at F.11 (370 molecules/100 ng total RNA) and peaked in abundance at E18 (640,000 molecules), corresponding to a 1730-fold increase (Fig. 3a). Over E11-E14, the number of GAD transcripts increased exponentially, doubling every $9 \mathrm{hr}$, then tapering off between E14 and E18, with an additional daily accumulation of 125,000 new mRNA molecules. Starting at E18, transcript abundance declined approximately twofold every $14 \mathrm{~d}$ (adult level, 159,000 molecules). Thus, GAD65 mRNA expression is characterized by an initial exponential growth phase that reached its maximum at E18 and then declined.

Since EP10 is coamplified with GAD67, it is conceivable that competition in the PCR reaction led to a bias in the GAD67 results during the embryonic period, when EP10 and GAD67 transcripts were expressed at similar levels. Hence, we conducted an alternative determination of GAD67 mRNA to estimate this error, based on GAD67 $7_{\text {corccted }}=R_{\mathrm{GAD67/EP10}} \cdot \mathrm{EP} 10$. $R_{\mathrm{GAD} 67 / \mathrm{EP} 10}$ was calculated from the estimated number of molecules from the coamplification experiment (left inset, Fig. 3b), in which the molecular ratio should have remained constant, even while taking into account some competition. Therefore, GAD67 ${ }_{\text {corrected }}$ represents an estimate of GAD67 expression that should compensate for the experimental error induced by competition with EP10. Since the number of GAD67 transcripts estimated by the two protocols was comparable (right inset, Fig. $3 b$ ), we used the direct determination of GAD67 transcript abundance in our analysis.

During E11-E13, GAD67 transcripts were detected at a relatively constant level of $214 \pm 74$ molecules (Fig. $3 b$ ). GAD67 mRNA expression increased 1300 -fold to a maximum of 280,000 molecules at P0, after which it declined gradually by a factor of 3.4, culminating in the adult level of 83,000 molecules. From E13 through E16, GAD67 mRNA doubled every $9.6 \mathrm{hr}$. From E16 to P0, GAD67 transcripts grew at a rate of 31,000 molecules per day to the maximum at $\mathrm{P} 0$. During postnatal development, GAD67 mRNA levels diminished by a factor of 2 every $13 \mathrm{~d}$, to plateau at the adult level. Thus, after a $2 \mathrm{~d}$ delay, the pattern of GAD67 mRNA expression largely paralleled that observed for GAD65 transcripts. The time course of the putative precursor of GAD67 and EP10 mRNA, pre-GAD67, shown as the sum of GAD67 and EP10 transcripts in Figure $3 b$ (broken line), also qualitatively resembled that of GAD65.

At E11, 400 molecules of EP10 mRNA were detected, increasing 53-fold over the next $6 \mathrm{~d}$ to a peak of 21,000 molecules at E16 (Fig. 3c). A precipitous, 700-fold decline began thereafter and continued throughout the postnatal period to the adult level of 30 molecules/100 ng total RNA. Between E11 and E14, transcript numbers doubled every $13 \mathrm{hr}$, while during the late prenatal period (E16-E21) transcripts decreased by a factor of 2 every $34 \mathrm{hr}$. A slower rate of decline occurred during the postnatal period, with expression diminishing twofold every $4.2 \mathrm{~d}$. Hence, EP10 mRNA was transiently expressed during embryonic development.

\section{GAD MRNA is transiently distributed throughout the developing cervical cord}

The tissue distribution of GAD transcript expression in sections of cervical spinal cord was visualized in autoradiograms with a probe hybridizing to a segment common to the GAD67 and EP10 sequences (Fig. 1). The in situ signals were therefore representative of pre-GAD67 expression (see above). During embryogenesis, hybridization signals were observed in a majority of cells throughout the cervical cord (Fig. 4). After birth, the signals became progressively more restricted to cells in the dorsal horn region of the cord. The developmental distribution of GAD65 transcripts (not shown) closely paralleled the emergence and progressive anatomical restriction of pre-GAD67 mRNAs. Thus, the transient abundance of GAD family transcripts measured with RTPCR corresponded to a transient expression in many cells throughout the cervical cord.

\section{$G A D$ family $m R N A$ expressions parallel those of nestin and neurofilament}

We compared the expression of transcripts encoding nestin, neu. rofilament light (NFL) and medium (NFM) proteins to GAD family mRNAs using QRTPCR (Fig. 5). Maximal levels of the neuroprogenitor marker nestin clearly preceded neurofilament and GAD induction (Fig. $5 a$ ). Both nestin and EP10 transcripts were markedly reduced in the adult, emphasizing the expression of EP10 mRNA during neurogenesis. Parallel to GAD65 and GAD67 mRNA expression, NFL and NFM transcripts were both detectable at E13, and reached their maximum expression at E18 before attaining reduced adult levels (Fig. $5 b$ )

\section{EP10 transcript expression declines as proliferation ceases}

The detection of significant numbers of EP10 transcripts was virtually limited to the embryonic period. Since one of the most widely recognized features of the embryonic period of cervical cord development is the generation of neuroblasts, we compared EP10 mRNA expression with the number of cells found in the cervical region, the number of cells synthesizing DNA (identified with anti-BrdU antibodies), and the number of cells simultaneously expressing immunoreactivity for EP10-GAD67 protein and for BrdU during the embryonic period (Ma et al., 1992; D. Maric, unpublished observations). A polyclonal antibody, K2, recognized both EP10 and GAD67 protein (EP10-GAD67, analogous to pre-GAD67 mRNA; see above), as shown in Western blots (Behar et al., 1993a), which is consistent with the fact that EP10 protein shares $>90 \%$ sequence homology with GAD67. Because EP10 transcript expression exceeded GAD67 mRNA abundance up to E14 (Fig. 3), and since EP10 translation products were also apparent in Western blots of embryonic cervical cord homogenates (Behar et al., 1993a), a significant proportion of early $\mathrm{K} 2$ immunostaining can be attributed to the EP10 gene product. Expression of EP10 mRNA, total cell number, number of BrdU-immunoreactive cells, and number of BrdU and EP10GAD67 protein coimmunoreactive cells all exhibited exponen- 



을

政

西要

군

.

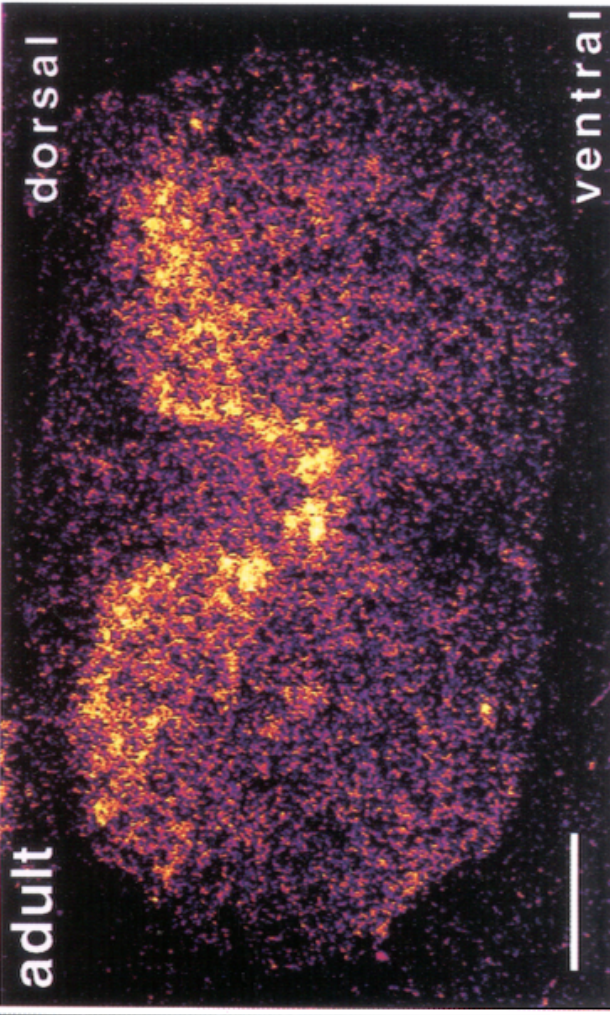

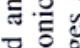

을 츨

के ऐ

ज ธँ

드응

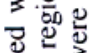

疍 $\overline{3}$

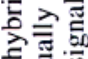

证

उ急

동홍응

플

क्ष

氖

든

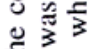

垔. 3

ㅇํㅇ

的要

记列

垔

능

홍ㅎำ

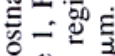

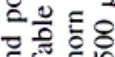

至的的

记氧

证证

危的

㝳氙

응

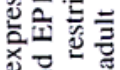

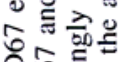

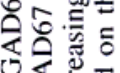

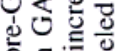

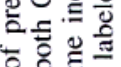

它施

鱼.

응

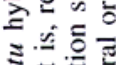

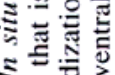

중응

论。 
a

Nestin
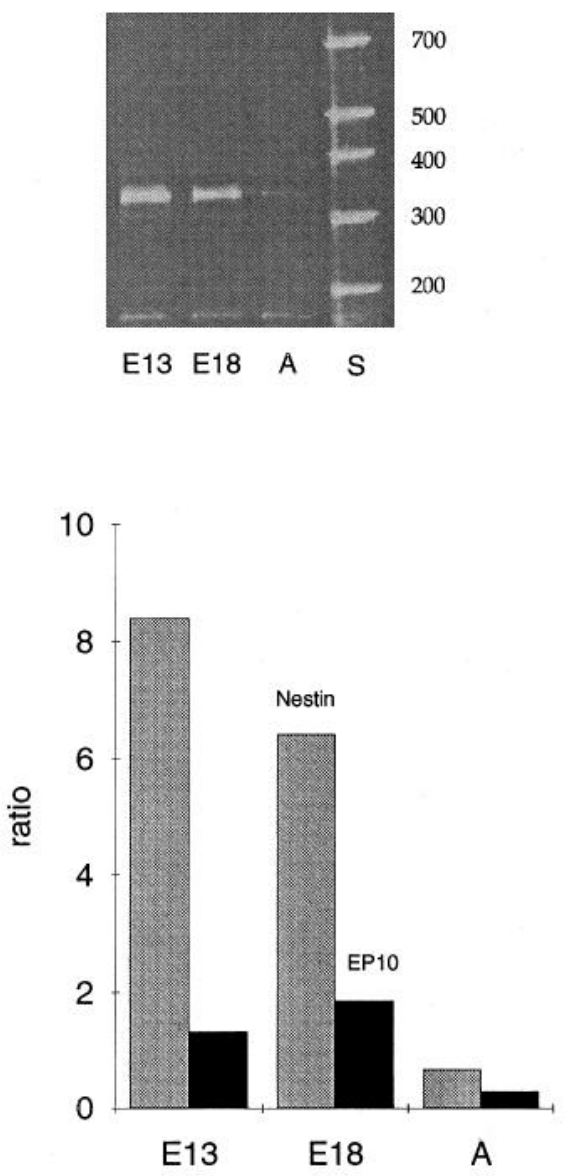

age
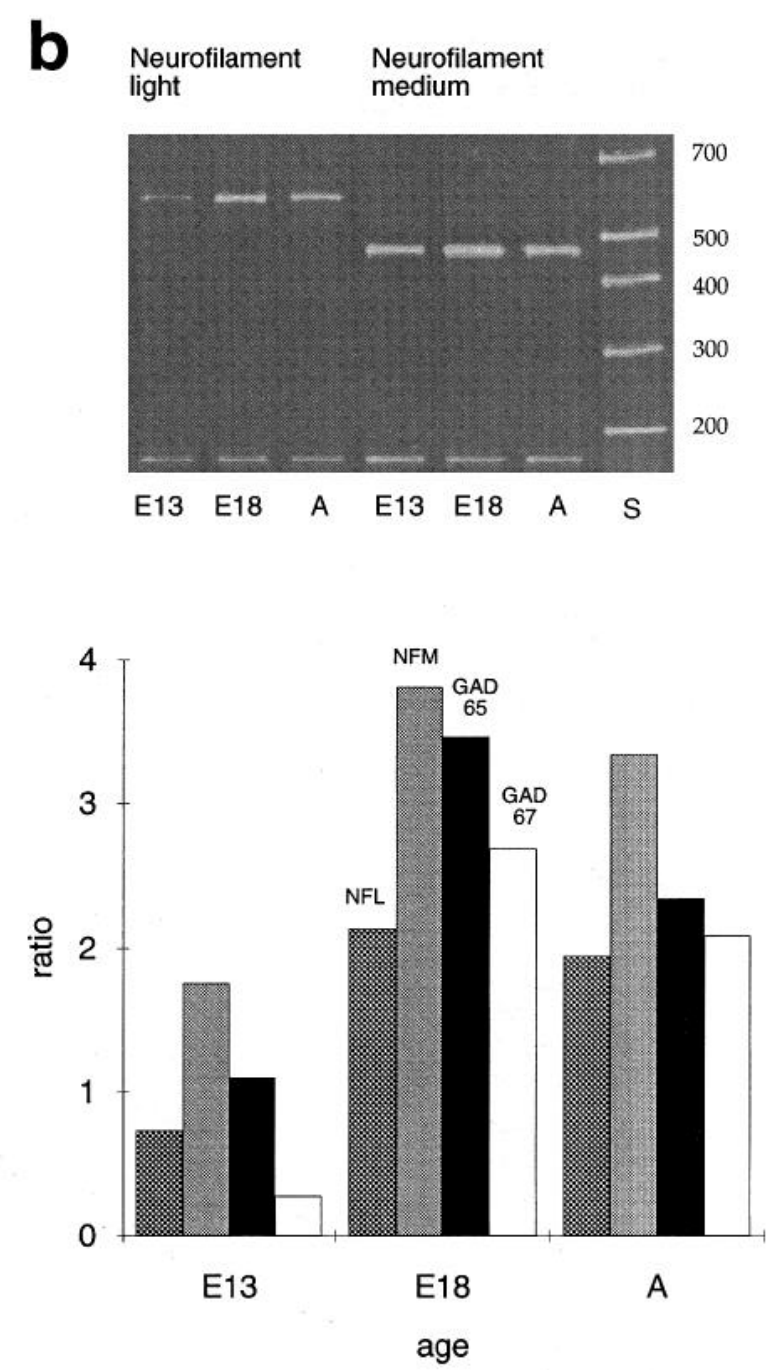

Figure 5. Parallel expression of developmental markers and GAD family transcripts. The top panels show ethidium bromide-stained polyacrylamide gels of quantitative hot-start RTPCR products derived from E13, E18, and adult cervical spinal cord total RNA, and control RNA as an internal standard (149 bp). The sample/control band ratios (see above) are graphed in the bottom panels for the respective reaction products depicted here and for the GAD mRNA amplification experiments. $a$, Comparison of nestin (350 bp) and EP10 mRNA (244 bp) expression. $b$, Abundance of transcripts for the neuronal markers neurofilament light $(N F L ; 612 \mathrm{bp})$, medium (NFM; $462 \mathrm{bp})$ in comparison to GAD65 and GAD67 mRNA expression.

tially increasing and decreasing phases, each shifted by $1-2 \mathrm{~d}$ with respect to the other parameters (Fig. $6 a$ ).

To clarify the relationships among the parameters plotted in Figure $6 a$, we have transformed the data by computing the slope (daily rate of change with respect to the next day), for each parameter. When EP10 mRNA showed the greatest rate of increase at E13 (Fig. 6b, EP10 panel), the relative number of proliferative elements (Fig. $6 b$, BrdU-IR panel) decreased maximally. Moreover, there was no change in the number of proliferative, BrdU-IR cells also immunoreactive for EP10GAD67 (slope $=0$ ), which exhibited a maximal rate of decrease at E14 (Fig. 6b, BrdU\&GAD-IR cells panel). In addition, the rate of growth in cervical spinal cord cell number slowed at E13, reached a steady state over E14-E15, and decreased at E16 as a significant proportion of cells disappeared (Fig. $6 b$, total cells panel). The decline in the size of the cervical spinal cord cell population coincided with a reduction in EP10 gene expression (Fig. 6a). In summary, transient expression of EP10 mRNA was associated with the developmental switch from proliferation to differentiation. During subsequent maturation, EP10 mRNA expression essentially ceased, probably because the alternative splicing of pre-GAD67 (see below) favored GAD67 transcripts, as shown by the continued elevation of pre-GAD67 (Fig. 3).

Early GAD family transcript appearance coincides with the advent of $G A B A, G A B A_{A}$ receptor family $m R N A s$, and functional $G A B A$ receptors

Since we are uncertain what contribution was made by each of the three GAD transcript family members to GABA production, we arithmetically summed the transcript numbers of all three members to obtain a single parameter summarizing GAD family expression during development. Three distinct phases corresponding to a steep increase in the early embryonic period, followed by saturation, and progressive reduction in the postnatal period to adult levels were also apparent when the summed GAD family mRNAs were plotted logarithmically as a single parameter (Fig. 7a). We also plotted the single parameter data on a linear scale and as the first derivative or slope (Fig. 7a). 

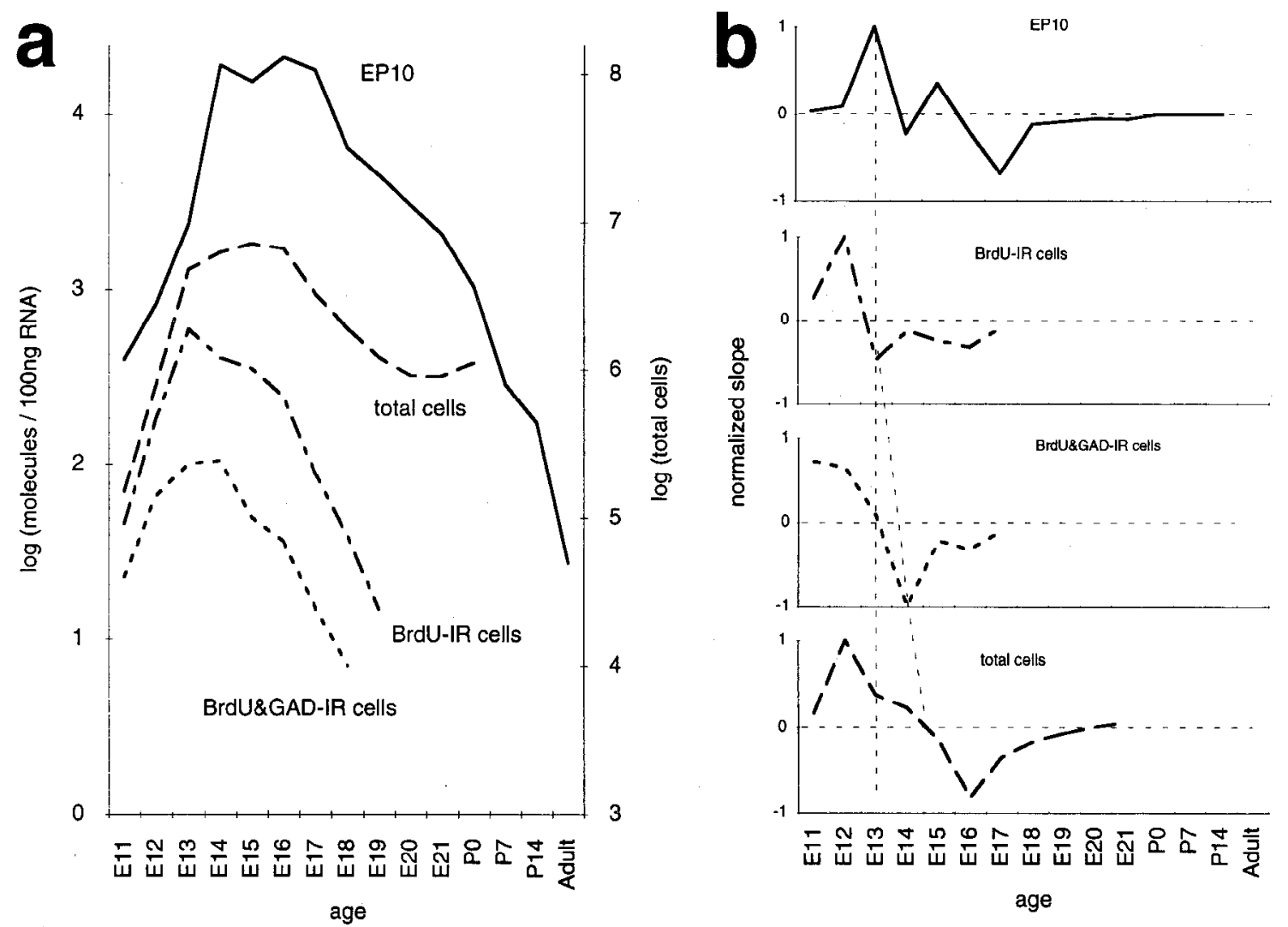

Figure 6. EP10 expression during the transition from proliferation to differentiation in the cervical spinal cord. a, Time course of EP10 transcript expression, total cells recovered from dissociates of the cervical spinal cord, total BrdU-IR cells in the cervical cord, and number of combined BrdU-IR and EP10-GAD67 immunoreactive cells (Ma et al., 1992; Maric, manuscript in preparation), from top to bottom. All parameters show a similar steep embryonic increase and decrease, shifted by $1-2 \mathrm{~d} . b$, Normalized slope (daily rate of change with respect to the next day) of curves shown in $a$. The slope accentuates changing trends with respect to EP10 mRNA expression (panel 1), the number of proliferative cells (panel 2), correlation of dividing cells with EP10-GAD67 expression (panel 3), and total cell number (panel 4). The dotted line drawn across all panels at E13 marks the maximal rate of increase in EP10 mRNA expression to emphasize the correlation to the other parameters. The diagonal line across the three bottom panels suggests a sequence of events, beginning with a loss of proliferating cells, followed by a reduction in dividing cells expressing EP10-GAD67, culminating in a halt of proliferation.

During E12-E14, the slope of the single parameter data was virtually identical to the data plotted on the linear scale, as would be expected for the derivative of an exponential function. This observation and the practically linear increase of $\log N_{\mathrm{mRNA}}$ over E11-E14 demonstrated that the earliest phase of GAD family transcript expression followed a precisely exponential time course.

The early increase of GAD mRNA expression during neurogenesis naturally prompted speculation on the physiological roles of these activated GAD genes. In this context, we plotted the summed GAD family transcript data together with measurements of GABA production and the emergence of $\mathrm{GABA}_{\mathrm{A}}$ receptors (Fig. 7b). GABA was detected immunocytochemically in acutely isolated cervical spinal cord cells as early as E15, when 7\% were immunopositive (Schaffner et al., 1993). The cellular distribution subsequently increased fivefold to its maximum at E19 (35.8\% of dissociated cells), and then declined to $4 \%$ at P5. The time course of immunodetectable GABA closely paralleled GAD family gene expression $(R=0.98)$.

We previously studied the advent of $\mathrm{GABA}_{\mathrm{A}}$ receptor family transcripts in the cervical spinal cord using in situ hybridization and the RTPCR technique (Ma et al., 1993). For simplicity, we plotted the normalized average of PCR-amplified signals for 13 members of the GABA $A_{A}$ receptor family $\left(\alpha_{1-6}, \beta_{1-3}, \gamma_{1-3}, \delta\right)$ dur- ing cervical spinal cord development. Although not as precise as quantitative PCR, the data clcarly demonstrated a relative increase of $\mathrm{GABA}_{\mathrm{A}}$ receptor family transcript expression during the embryonic period from $23 \%$ of maximum at $\mathrm{E} 12$ to $100 \%$ at P0, parallel to the ontogeny of GAD family transcripts. Furthermore, $\mathrm{GABA}_{\mathrm{A}}$ receptor family mRNAs decreased during the postnatal period to $74 \%$ of maximal expression. $\mathrm{GABA}_{\mathrm{A}}$ receptor and GAD expressions during development were highly correlated $(R=0.99)$.

Functional $\mathrm{GABA}_{\mathrm{A}}$ receptors have been characterized with digital video microscopic recordings of acutely cultured, cervical spinal cord cells treated with a voltage-sensitive dye. At E13, $21 \%$ of cervical spinal cord cells exhibited depolarizing responses to muscimol, a $\mathrm{GABA}_{\mathrm{A}}$ receptor agonist (Fig. $7 b$; Walton et al., 1993). The fraction of responding cells increased at E14 to $50 \%$ and at E15 to $79 \%$, precisely paralleling the steep rise in both $\mathrm{GAD}$ and $\mathrm{GABA}_{\mathrm{A}}$ receptor family transcript expressions. It then remained relatively constant during the remainder of the embryonic period, analogous to the semistationary phase of $\mathrm{GAD}$ and $\mathrm{GABA}_{\mathrm{A}}$ receptor family transcript expressions. These two parameters, the induction of GAD mRNA and the percentage of cells exhibiting depolarizing responses to muscimol, were highly correlated $(R=0.97)$. 

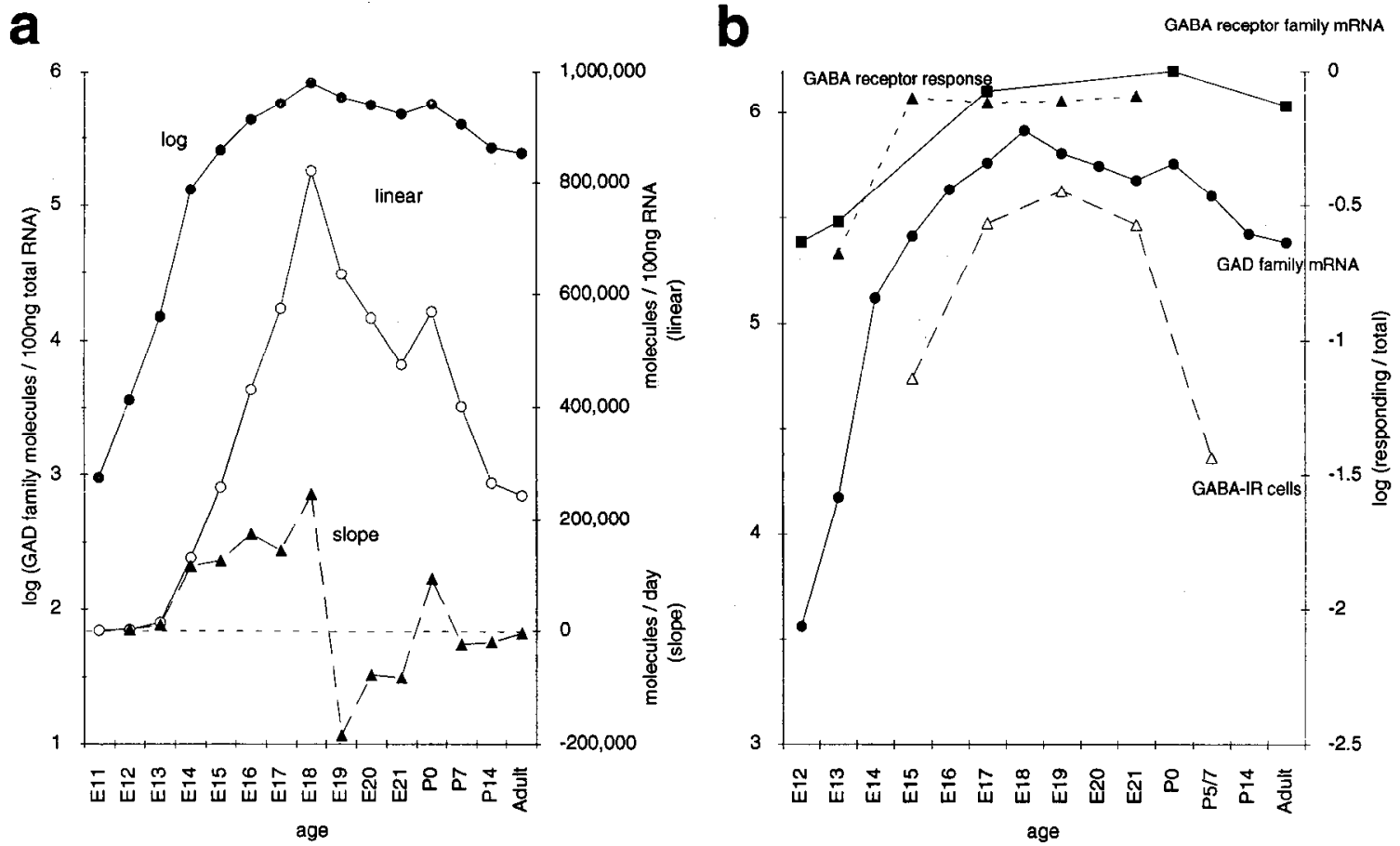

Figure 7. Parallel expression of cumulative GAD family transcripts, GABA immunoreactive cells, GABA $\mathrm{A}_{\mathrm{A}}$ receptor family mRNA, and GABAevoked pharmacological responses. $a$, Comparison of GAD family mRNA abundance on logarithmic and linear scales, to the slope of GAD transcript expression. GAD65, GAD67, and EP10 transcripts were summed, giving an overview of GAD expression during development. The slope was calculated in daily intervals up to P0, and in extended intervals during postnatal development. Note the parallel time course of total GAD and its derivative, that is, slope up to E14, signifying an exponential relationship. $b$, The time course of cumulative GAD family mRNA abundance closely correlates with the physiological and structural development of the GABA signaling system. The expression of GABA receptor mRNAs was measured with standard RTPCR and is plotted here as the normalized average of PCR product band intensities over 13 different GABA receptor subunits $\left(\alpha_{1-6}, \beta_{1-3}, \gamma_{1-3}, \delta\right.$; Ma et al., 1993). GABA $A_{A}$ pharmacological responses are depicted as the fraction of spinal cord cells that depolarize in response to muscimol, a GABA agonist (Walton et al., 1993). The expression of $\mathrm{GABA}_{\mathrm{A}}$ receptor subunit transcript abundance (squares) and the fraction of muscimol-responding cells (solid triangles), grew in concert with GAD mRNA expression (circles) $(R=0.99$ and $R=0.97$, respectively). The fraction of GABA-immunopositive cells (Schaffner et al., 1993) correlates well with the time course of GAD transcript abundance up to E21 $(R=0.98)$.

\section{A formal feedback model for the transcriptional regulation of GAD65 and pre-GAD67}

Figures 3 and 8 show that the steep, exponential phase of embryonic GAD transcript induction took place between E11 and E14 for GAD65 and between E11 and E16 for pre-GAD67. These kinetics can be explained by a positive feedback regulating GAD mRNA expression. Evidence for components possibly involved in such a positive feedback system, such as expression of GABA, a variety of $\mathrm{GABA}_{\mathrm{A}}$ receptor subunits, GABA-activated depolarizing $\mathrm{Cl}^{-}$conductance and cytosolic $\mathrm{Ca}^{2+}$ elevation at this stage of development is at hand (see above and discussion). A hypothetical signaling chain could be based on the scheme

$$
\mathrm{GAD} \rightarrow \mathrm{GABA} \rightarrow \mathrm{GR} \rightarrow\left[\mathrm{Ca}^{2+}\right]_{\mathrm{cyt}} \rightarrow \mathrm{PP} \rightarrow \mathrm{TF} \rightarrow \mathrm{GAD}
$$

GAD catalyzes production of GABA, which is secreted and stimulates GABA receptors, GR, in the same and in neighboring cells. Through ionotropic and metabotropic receptors (GR), this leads to changes in the cytosolic $\mathrm{Ca}^{2+}$ concentration $\left(\left[\mathrm{Ca}^{2+}\right]_{\text {cyt }}\right)$ and consequently in protein phosphorylation (PP) due to $\mathrm{Ca}^{2+}$ activation of protein kinases and phosphatases (e.g., $\mathrm{Ca}^{2+} / \mathrm{cal}-$ modulin-dependent protein kinases, phosphatases, etc.). This results in activation of trans-acting factors, TF, finally culminating in transcriptional activation of GAD. Although it is not yet certain which exact signaling molecules are regulated by $G A D$, we apply Occam's razor and cumulatively represent all of these parameters by the rate constant $\gamma^{\prime}$ (see below).

A generalized description of transcriptional regulation involves generation of mRNA $(M)$ from nucleotide precursors $(N)$ and degradation of $M$ into $N$ :

$$
N \frac{g(M)}{\sqrt{d(M)}} M
$$

We postulate feedback functions governing the rate of generation and degradation: $g(M)=$ generation rate of $M$ as function of $M$ (positive feedback), $d(M)=$ degradation rate of $M$ as function of $M$ (negative feedback). $d(M)$ is also a measure of the halflife of the mRNA according to $t_{1 / 2}=\ln 2 / d(M)$. We can now formulate the rate law for $M$ :

$$
\frac{d M}{d t}=g(M) N-d(M) M .
$$

The feedback of $M$ on its own rate of generation is reflected in the term

$$
g(M)=\gamma^{\prime} M .
$$

We assume that $N=$ constant because fluctuations in the nucleotide pool concentration would have serious, nonselective effects on the transcription of all genes, not providing the specificity required for a discriminating regulatory network. We define that 


$$
\gamma=\gamma^{\prime} N
$$

and obtain the result

$$
g(M) N=\gamma M
$$

The rate of degradation is also a function of $M$, that is, degradation increases with accumulating mRNA:

$$
d(M)=\delta M
$$

In practical terms, this corresponds to a reduction of mRNA half-life (see above) with increasing transcript levels, that is, $t_{1 / 2}$ $=\ln 2 /[\delta M]$. The rate law for $M$ is now a function of $M$ and two parameters:

$$
\frac{d M}{d t}=\gamma M-\delta M^{2}
$$

Integration of this rate law,

$$
\int \frac{d M}{(\gamma-\delta M) M}=\int d t
$$

results in the expression

$$
\frac{\ln M}{\gamma-\delta M}=t+C
$$

which can be solved according to $M$ :

$$
M(t)=\frac{\gamma}{e^{-\gamma(t+C)}+\delta}
$$

This equation resembles the Verhulst equation for exponential growth with saturation in population dynamics. It is expressed in a parameterized form:

$$
M(t)=\frac{M_{0} \gamma e^{\gamma t}}{\gamma+\delta M_{0}\left(e^{\gamma t}-1\right)}, \quad M_{0}=\frac{1}{\frac{1}{\gamma}\left(e^{-\gamma C}+\delta\right)} .
$$

This expression allows the determination of the extrema of $M$ at $t=0$ and $t=\infty: t=0, M=M_{0} ; t=\infty, M=\gamma / \delta=M_{\infty}$. Close to $t=0, M$ will increase exponentially at a rate of $\gamma$. With progressing $t$, the slope will decrease, and $M$ will gradually approach $M_{\infty}$. This behavior is apparent in the $M(t)$ curves calculated for GAD65 and pre-GAD67 in Figure $8, b$ and $d$, respectively.

In principle, it is not mandatory to distinguish between the level of expression per cell, and the fraction of all cells expressing GAD, since GABA produced by one cell can affect that same cell and its neighbors. The tissue could then be considered as a functional unit with regard to regulation. But, the in situ hybridization data showed GAD expression being progressively restricted to the dorsal cord during postnatal development. We interpret this as a postnatal decrease in the number of cells possessing the necessary complement of transcriptional regulators enabling them to express GAD and respond to a GAD/GABA feedback. The postnatal reduction of GAD represents a decline in the fraction of cells, $R$, able to respond positively to GAD, $R$ $=$ (responsive cells)/(total cells). As an initial approach, we assume a general sigmoidal relationship for $R$ as observed in the time course of late embryonic and postnatal GAD expression from $R=R_{0}$ (embryonic) to $R=R_{\infty}$ (adult):

$$
R(t)=\frac{R_{0} t_{c}^{n}+R_{\infty} t^{n}}{t_{c}^{n}+t^{n}} .
$$

For simplicity, we presumed that $R_{0}=1$, that is, that virtually all cells are responsive to a positive GAD feedback during embryonic development (in accord with the in situ hybridization evidence):

$$
R(t)=\frac{t_{c}^{n}+R_{\infty} t^{n}}{t_{c}^{n}+t^{n}}
$$

The parameters are interpreted as follows: $t=0, R=1 ; t=$ $\infty, R=R_{\infty} ; t=t_{c}, R=0.5\left(1+R_{\infty}\right) ; n=$ exponent describing steepness of curve. The average expressed mRNA recovered from all cells can then be described by the product of the transcript abundance in responsive cells, $M(t)$, and the fraction of responsive cells, $R(t)$. The complete equation for the description of GAD mRNA expression is thus

$$
M_{\mathrm{tot}}(t)=R(t) \cdot M(t)=\frac{t_{c}^{n}+R_{\infty} t^{n}}{t_{c}{ }^{n}+t^{n}} \cdot \frac{\gamma}{e^{-\gamma(t+C)}+\delta} .
$$

Based on this equation, we numerically fitted the experimental data for GAD65 and pre-GAD67 using a least-squares fitting routine (Fig. 8; see figure legend for parameter values). The values calculated from this model closely approximates the experimental results obtained for GAD65 $(R=1.00)$ and preGAD67 $(R=0.99)$ mRNA expression. $\gamma$, or the doubling time, $t_{d}\left(t_{d}=\ln 2 / \gamma\right)$, describes the rate of increase during the early exponential inductive phase (Fig. $8 ; t_{d}=8.9 \mathrm{hr}$, GAD65; $t_{d}=$ $14.7 \mathrm{hr}$, pre-GAD67), closely resembling the rate constant derived from a single exponential fit (insets, Fig. 8a,c) between E11-E14 for GAD65 $\left(t_{d}=8.9 \mathrm{hr}\right)$ and E11-E16 for pre-GAD67 $\left(t_{d}=15.7 \mathrm{hr}\right)$.

The model predicts the time course of GAD mRNA half-life. Because the negative feedback relationship only applies to the population of cells that express GAD, $M(t)$, the half-life will be determined by $\delta$ and $M(t)$, according to $t_{1 / 2}(t)=\ln 2 /[\delta M(t)]$ (Fig. $8 b, d$; also see above). During early embryonic development, the half-lives of GAD65 and prc-GAD67 mRNAs decrease exponentially. We observed saturation as they reached the same value as the doubling times, $t_{d}$, resembling the steady state of mRNA expression.

The generation of GAD67 and EP10 mRNAs can be approximated by an alternative splicing term

We make the first-order assumption that GAD67 and EP10 transcripts are alternative splicing products of the same precursor mRNA, pre-GAD67. Therefore, a proper description of their regulation requires a three-step model for transcription, RNA editing, and degradation. Transcription and degradation have been detailed above. The time course of the alternative splicing ratio, $R_{\mathrm{EP} 10}=\mathrm{EP} 10 /$ pre-GAD67, as observed in the experiments, is calculated by taking the value of EP10 and dividing it by the sum of EP10 and GAD67, that is, pre-GAD67, at each time point. The resulting data are shown in Figure $9 a$ and resemble a biexponential embryonic and postnatal decrease, preceded by a maximum at E13. The biexponential decrease of $R_{\mathrm{EP} 10}$ can be described by the empirical relation 
a

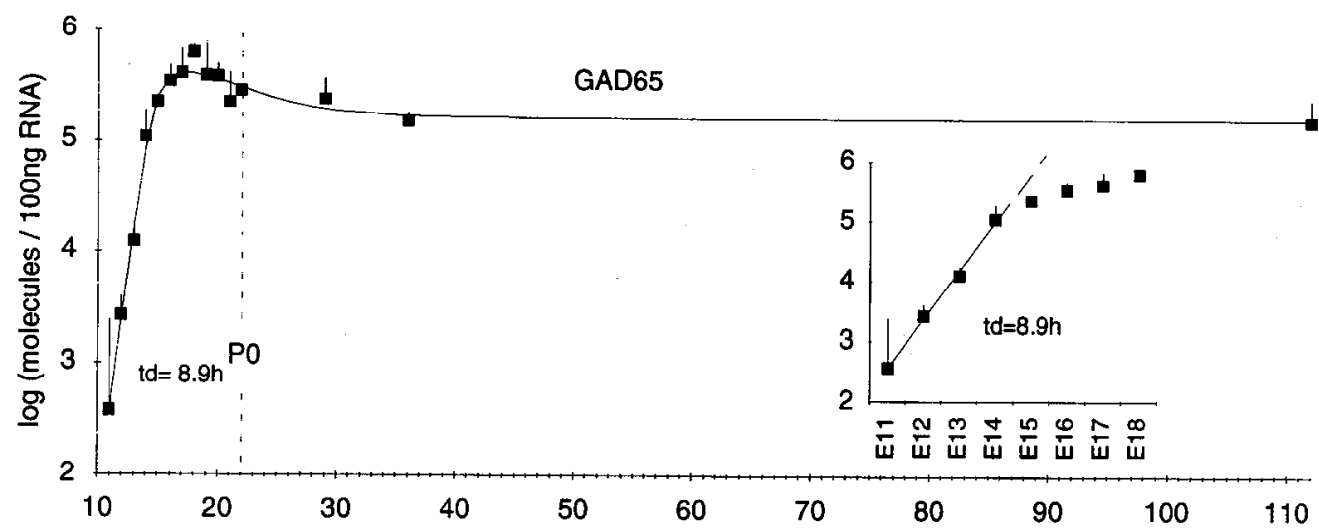

b
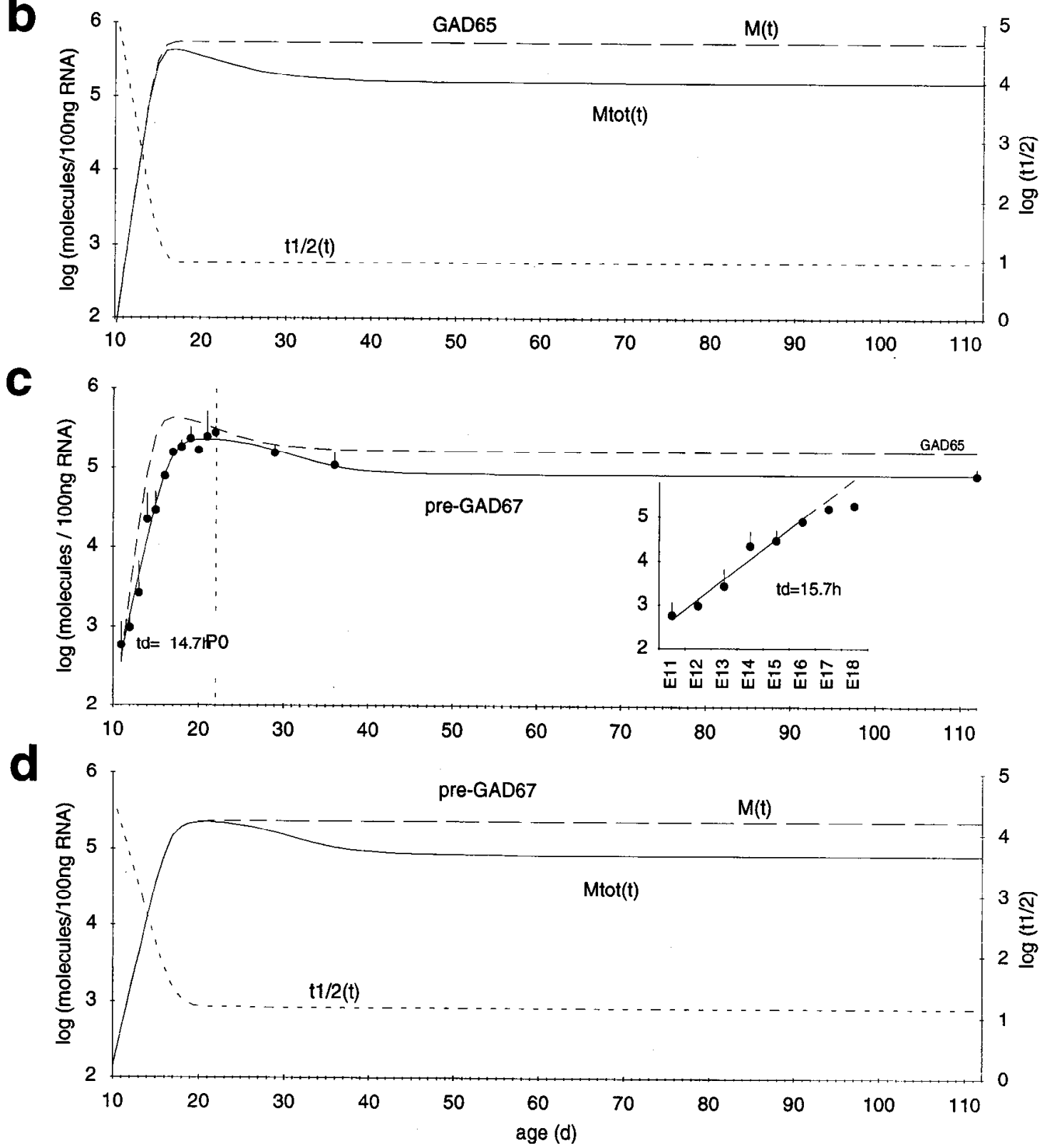

Figure 8. Quantitative modeling of the transcriptional regulation of GAD65 and pre-GAD67. The complete developmental time course of GAD mRNA expression, $M_{\mathrm{tot}}(t)$, was numerically fitted to an equation based on a model of positive and negative feedback control of expression, $M(t)$, combined with postnatal shifting of the anatomical distribution of mRNA abundance $\left[R(t)\right.$; see text]: $M_{\mathrm{tot}}(t)=R(t) \cdot M(t)=\left(t_{c}{ }^{n}+R_{\infty} t^{n}\right) /\left(t_{c}{ }^{n}+\right.$ $\left.t^{n}\right) \cdot \gamma /\left(e^{-\gamma(t+C)}+\delta\right)$. The solid lines represent the calculated time course of GAD transcript expression, superimposed on the measured values and positive SD error bars in $a$ and $c$. The broken lines in $b$ and $d$ depict the time course of GAD mRNA expression restricted to the responsive cell population. The model predicts the time course of mRNA half-life, dotted lines in $b$ and $d$, according to $t_{12}=\ln 2 /[\delta M(t)]$. The time axis is defined on an extended embryonic age scale, that is, $20 \mathrm{~d}=\mathrm{E} 20,22 \mathrm{~d}=\mathrm{P} 0$, and $112 \mathrm{~d}=\mathrm{P} 90=$ adult. $a$, Developmental expression of GAD65 mRNA. 


$$
\begin{aligned}
R_{\mathrm{EP} 10_{\text {decreasing }}} & =\frac{a_{1} e^{-\lambda_{1} t}+a_{2} e^{-\lambda_{2} t}}{a_{1} e^{-\lambda_{1} t}+a_{2} e^{-\lambda_{2} t}+1} \\
& =\frac{1}{1+\frac{1}{a_{1} e^{-\lambda_{1} t}+a_{2} e^{-\lambda_{2} t}}}
\end{aligned}
$$

The early increasing phase can be approximated as

$$
R_{\mathrm{EP} \mid 0_{\text {increasing }}}=\frac{1}{b e^{t}+1}
$$

The product of both expressions is sufficient to characterize the total time course of $R_{\mathrm{EP} 10}$ :

$$
R_{\mathrm{EP} 10}=\frac{1}{1+\frac{1}{a_{1} e^{-\lambda_{1} t}+a_{2} e^{-\lambda_{2} t}}} \cdot \frac{1}{b e^{-t}+1} .
$$

The calculated values from the fitted equation closely approximate the measured time course $(R=1.00)$. Note that the switch from the first to the second exponentially decreasing phase coincided exactly with the transition from embryonic to postnatal development. Without the slower, second exponential decline, the extrapolated curve predicts that EP10 will fall clearly below detectable levels in the adult.

Since the alternative splicing ratio for GAD67 can be directly obtained from $R_{\mathrm{EP} 10}$, that is, $R_{\mathrm{GAD} 67}-1-R_{\mathrm{EP} 10}$, unle canl nuw calculate the time course of GAD67 by multiplying the expressions for pre-GAD67 and $R_{\mathrm{GAD} 67}$ at the previously fitted parameter values. The results show a close correlation between the measured and predicted values $(R=0.99)$ in Figure $9 b$. Here, the embryonic to postnatal transition do not correlate with a significant change of GAD67, since $R_{\mathrm{GAD} 67} \approx 1$.

Analogously, Figure $9 c$ shows that the product of the fitted curves for $R_{\mathrm{EP} 10}$ (solid line, Fig. 9a), and pre-GAD67 (broken line, Fig. $9 a$ ) result in a close approximation to the measured values of $\operatorname{EP} 10(R=0.99)$. The transition at P0 is clearly reflected in a postnatal stabilization of EP10 expression following the embryonic declining phase. In summary, the empirical formula for the ratio of alternative splicing, combined with the feedback model of pre-GAD67 expression, provided a numerically accurate description of the measured data for GAD67 and EP10.

\section{Discussion}

\section{Developmental expression of $G A D$}

Beginning at E11, GAD65 mRNA expression underwent an exponential growth phase, followed by a gradual increase at E15 to maximal mRNA levels at E18. Protein for GAD65 is initially detected at E17 in spinal cord homogenates using Western blotting for a $59 \mathrm{kDa}$ band with the 1440 antiserum for GAD65 (Behar, 1993a). Thereafter, G $\Lambda$ D65 protein increased, but reached its maximum level at $P 14$, while GAD65 mRNA already passed its apex. In the adult, GAD65 mRNA and protein are detected at levels moderately lower than maximal developmental expression. Expression of GAD65 protein does not immediately follow its mRNA during embryogenesis. This could be due either to a translational time shift, or a change in the stability, i.e., half-life of the protein. Moreover, detection of GAD65 protein with antibodies may not exhibit the same sensitivity as the RTPCR technique for transcript detection. Even low concentrations of GABA produced by not yet detectable levels of GAD65 could mediate signals; GABA induces intracellular $\mathrm{Ca}^{2+}$ mobilization in the $10^{-18}$ to $10^{-16} \mathrm{M}$ range in embryonic cortical cell suspensions (Maric et al., 1993) and chemokinesis in the femtomolar range in embryonic cervical spinal cord cells at E13 (Behar, 1993b).

Although levels of GAD67 and GAD65 mRNA were comparable at E11, the former remained stable over the next $48 \mathrm{hr}$ before being upregulated. This may have been due to the asymmetric differential splicing of the pre-GAD67 transcript into EP10 and GAD67 mRNAs (discussed below). The exponential phase of GAD67 mRNA induction, as well as for GAD65, lasted for $4 \mathrm{~d}$, with almost identical doubling time to GAD65. A gradual increase through the end of prenatal development culminated in maximal expression at P0, followed by a decline to adult levels, approximately threefold lower than maximal. In Western blots of spinal cord homogenates, a $71 \mathrm{kDa}$ band representing GAD67 can be detected at E13 using the K2 antiserum (Behar, 1993a). Increasing band intensities for GAD67 protein then followed a time course similar to the $59 \mathrm{kDa}$ GAD65 bands. Although GAD67 protein was detected before GAD65 in the Western blots, it is not clear that GAD67 necessarily preceded GAD65 protein expression, since the Western blots were not calibrated, i.e., polyclonal antibody affinities may have varied significantly. An unequivocal comparison of GAD mRNA and GAD protein expression is not yet possible, since corresponding quantitative data on protein levels at the temporal resolution of the data presented here for mRNA expression is unavailable.

The alternatively spliced transcript of GAD67, EP10, exhibited an embryonically restricted expression. Detected at levels comparable to GAD65 and GAD67 at E11, EP10 mRNA levels sharply increased until E14 and remained stable from E14 to E17. This was followed by a steep decline until PO, and another, slowly decreasing phase, reducing EP10 expression to its adult levels, that is, 700 -fold lower than the maximum. The ontogeny of EP10 mRNA most closely approximated Western blot analysis of its corresponding, enzymatically active $\sim 44 \mathrm{kDa}$ protein (Behar et al., 1993a, Szabo et al., 1994). An increase of Western signals can also be observed between E13 and E17, followed immediately by a steady decline from E17 to adult.

\section{EPlO expression is correlated with the transition from proliferation to differentiation}

GAD67 gene-derived proteins are initially detected in dividing cells during the proliferative period (Ma et al., 1992). S-phase

The inodel provides an accurate description of the measured data $(R=1.00)$. Parameler values for the filted curve: $\gamma=1.87, R_{c}=0.285, t_{c}=$ $20.1, n=5.59, C=-8.15, \delta=0.00000340 . b, M(t)$ and $t_{1 / 2}(t)$ calculation for GAD65 mRNA expression. Same parameter values as in $a$. $c$, Time course of pre-GAD67 transcript expression. The fitted time course of GAD65 is shown as a broken line for comparison. The calculated values are in excellent agreement with the experimental results $(R=0.99)$. Parameter values for the fitted curve: $\gamma=1.13, R_{\infty}=0.356, t_{c}=29.3, n=8.83$, $C=-5.75, \delta=0.00000480 . d, M(t)$ and $t_{1 / 2}(t)$ calculation for pre-GAD67 transcript abundance. Same parameter values as in $c$. The insets in $a$ and $c$ depict a simple exponential fit, which provides a good first approximation to the early embryonic expression of GAD65 mRNA between E1 1 and $\mathrm{E} 14(R=1.00)$ and pre-GAD67 transcripts from E11 to E16 $(R=0.96)$, respectively. The respective doubling times, $t d$, closely agree with the $t d$ s (shown on left) of the single exponential phase of the general model (see text for details). 

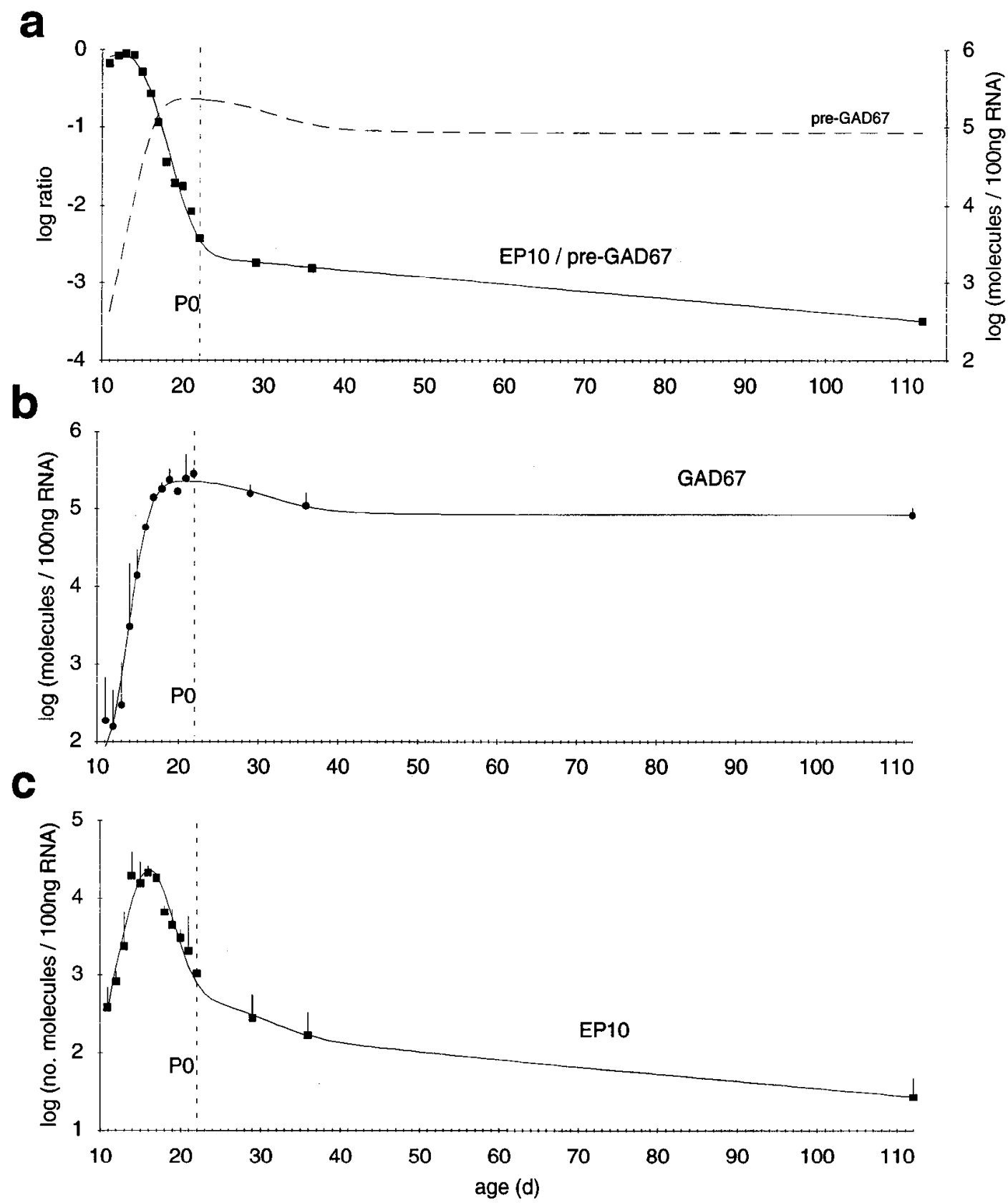

Figure 9. Developmental generation of EP10 and GAD67 mRNAs by alternative splicing of pre-GAD67 transcripts. The solid lines represent the calculated time course of GAD transcript expression, superimposed on the measured values and positive SD error bars. The time axis is defined on an extended embryonic age scale as in Figure 8. a, EP10 mRNA as a fraction of pre-GAD67 transcripts. The experimental ratios were calculated from the measured data for EP10 and GAD67 mRNAs as according to $R_{\mathrm{EP} 10}=N_{\mathrm{EP} 10} /\left(N_{\mathrm{GAD} 67}+N_{\mathrm{EP} 10}\right)$. These values were numerically fitted to an empirical equation based on a double exponential decrease of $R_{\mathrm{EP} 10}$ (see text): $R_{\mathrm{EP} 10}=1 /\left[1+\left(1 /\left[a_{1} e^{-\lambda_{1} t}+a_{2} e^{-\lambda_{2} t}\right]\right)\right] \cdot 1 /\left(b e^{-t}+1\right)$. The model provides an accurate description of the measured data $(R=1.00)$. For comparison, the time course of pre-GAD67 transcript expression (see Fig. $8 b$ and text) is included as a broken line. Parameter values for the fitted curve: $\lambda_{1}=0.95, \lambda_{2}=0.021, a_{1}=1,660,000, a_{2}=0.0034, b=12,600$. $b$, Time course of GAD67 mRNA expression. The calculated results for pre-GAD67 transcript expression and $R_{\text {EP10 }}$ are combined in the fitted curve according to (see text): $N_{\mathrm{GADG} 7}=N_{\mathrm{Pr}-\mathrm{GAD} 67} \cdot\left(1-R_{\mathrm{EP} 10}\right)$. The theoretical results are in excellent agreement with the experimental data $(R=0.99)$. $c$, Developmental expression of EP10 mRNA. EP10 mRNA expression was determined as the product of the theoretical curves for $R_{\mathrm{EP} 10}$ and preGAD67 transcripts (solid and dotted lines in $a$, respectively). For this complex relationship, the theoretical values are in remarkable accord with the experimental data $(R=0.99)$. Note the switch from the fast to the slow exponential decrease at birth ( $\mathrm{P0}$; also compare to $a)$.

cells, indicated by BrdU incorporation, are also labeled for EP10-GAD67 as early as E11 using the K2 antibody, which recognizes both GAD67 and EP10 protein (EP10-GAD67). Presumably the major early component of EP10-GAD67 was EP10, since it is the most abundant GAD protein detectable during early embryogenesis. The number of EP10 transcripts, distinct from GAD65 and GAD67 mRNAs, also closely paralleled the total number of cells isolated from the cervical spinal cord during prenatal development. In addition, EP10-GAD67 immunoreactivity is enriched in the neuroepithelial zone in E13, E14, and E16 cervical spinal cord sections. The neuroepithelial zone contains dividing cells, in the stage preceding migration and 
differentiation. Of all BrdU-positive cells in acute culture, 30$80 \%$ also expressed detectable EP10-GAD67 protein between E11 and E18, respectively. These data demonstrated that both EP10 mRNA expression and EP10-GAD67 immunoreactivity begin while cells are still dividing. The decline of mitotically active cells was paralleled by a reduction in EP10 mRNA expression, suggesting that no new cells were recruited for EP10 induction, while previously EP10 expressing cells terminated the production of this transcript. The correlation between decreased spinal cord cell number and loss of EP10 expression may suggest a role for GAD in programmed cell death. In fact, GABA has been shown to accelerate excitotoxic cell death in cortical cultures (Erdö et al., 1991). The parallel decline of the neuroprogenitor marker, nestin (Lendahl et al., 1990; reviewed in Nixon and Shea, 1992) and EP10 in late embryonic and postnatal development support a neurogenic role for EP10.

\section{The components of the GABA signaling system emerge in parallel}

The time course of GAD65 and GAD67 gene expression during embryogenesis of the cervical spinal cord is closely correlated with the expression of $\mathrm{GABA}_{\mathrm{A}}$ receptor subunit transcripts $(\mathrm{Ma}$ et al., 1993), immunocytochemically detectable GABA (Schaffner et al., 1993) and depolarizing responses to a $\mathrm{GABA}_{\mathrm{A}}$ agonist (Walton et al., 1993). In addition to the ontogenic parallels of these components of the GABA signaling system, GAD and $\mathrm{GABA}_{\mathrm{A}}$ receptor subunit transcripts are transiently overexpressed before the completion of embryogenesis. This is documented by RTPCR and in situ hybridization (Ma et al., 1993). The concerted expression of GAD family and $\mathrm{GABA}_{\mathrm{A}}$ receptor transcripts, coding for enzymatically active GAD and functional receptors, may form a regenerative network of GABA production and physiological signals having morphogenic functions.

\section{GAD family transcript expression parallels neurogenesis}

Ontogeny of the neuronal markers NFL and NFM mRNAs (Nixon and Shea, 1992) paralleled that of GAD65 and GAD67. All four transcripts were initially detected at E13, increased until E18, and exhibited reduced adult expression. GABA depolarizes a majority of ncurons acutcly isolated from the cmbryonic rat spinal cord beginning at E13 (Walton et al., 1993). Microelectrode recordings of motoneurons in hemisections of embryonic rat spinal cord show that GABA-mediated synaptic signals are depolarizing, triggering action potentials (Wu et al., 1992). In light of the differences between embryonic and postnatal GABA physiology, the earliest appearance of GAD and GABA may not only reflect the generation of a neuronal marker. GAD may participate in neurogenesis and the induction of neuronal markers.

GAD family induction: a model in the molecular physiology of development

The high sensitivity of QRTPCR permitted the analysis of GAD gene expression as a molecular physiological parameter, enabling the formulation of a quantitative model of its regulation. The exponential time course of early GAD65 and pre-GAD67 (putative forerunner of G $\Lambda \mathrm{D} 67$ and $\mathrm{EP} 10 \mathrm{mRN} \Lambda \mathrm{s}$ ) gene expression is indicative of a positive feedback loop driving their induction. The steady-state level of GAD mRNA production may result from a negative feedback, equivalent to a reduction of mRNA half-life. As a first test, we examined whether a mathematical model based on this hypothesis is consistent with the observed kinetics of GAD mRNA expression.
The principle that a signaling molecule regulates the expression of synthesizing enzymes and receptors has been demonstrated elsewhere in several related contexts. In the case of GABA, it has been shown that $\alpha_{1}$ and $\beta_{2}$ GABA $_{\mathrm{A}}$ receptor subunit mRNA expression can be induced by GABA in cerebellar granule cells (Kim et al., 1993). Positive feedback of a factor on its own expression was reported for induction of interleukin-1 (IL-1) mRNA production following application of IL-1 to mesangial cells (Zoja et al., 1992). Although GABA was shown to selectively downregulate GAD67 protein without affecting GAD65 protein or reducing transcripts coding for either form, the millimolar concentrations of GABA employed in these studies were supraphysiological (Rimvall and Martin, 1992; Rimvall et al., 1993). Much lower ambient GABA concentrations play regulatory roles; chemokinetic responses in embryonic spinal cord neurons are induced by GABA within femtomolar and nanomolar concentration ranges (Behar et al., 1993b). The negative feedback component of the model has been demonstrated in the regulation of acetylcholine. Choline acetyltransferase (ChAT) mRNA is downregulated in response to carbamylcholine in neuroblastoma cells (Salvaterra, 1992). The negative feedback by $\mathrm{GAD}$ on its own expression may have resulted from increased mRNA degradation. A role for mRNA catabolism has been demonstrated for nitric oxide synthase (NOS). Nitric-oxide-mediated downregulation of NOS is due to a 16-fold reduction in mRNA half-life without any change in the gene transcription rate (Yoshizumi et al., 1993).

Signaling components putatively involved in the regulation of GAD mRNA expression have been identified in CNS development. GABA synthesis requires $\mathrm{Ca}^{2+}$ in cultured embryonic spinal cord neurons (Spitzer et al., 1993). The presence in the developing cord of transcripts encoding GABA receptor subunits (Ma et al., 1993), GABA-mediated depolarization and $\mathrm{Ca}^{2+}$ fluxes (Walton et al., 1993; Reichling et al., 1994), may provide the physiological basis for changes in $\mathrm{Ca}^{2+}$ homeostasis mediating GABA induction. Furthermore, GABA also leads to $\mathrm{Ca}^{2+}$ release from ryanodine-sensitive intracellular stores in early cortical development (Maric, personal communication). This could provide an additional stimulus for GABA production, since elimination of $\mathrm{Ca}^{2+}$ release from intracellular stores depresses $\mathrm{G} A \mathrm{~B} \Lambda$ synthesis in embryonic neurons (Holliday et al., 1991).

Are all spinal cord cells capable of responding to intercellular signals affecting expression of GAD mRNA? Since GAD-derived GABA could physiologically affect the cell of origin as well as its neighbors in spinal cord cultures (Valeyev et al., 1993), a GABA-induced stimulation of GAD transcription could lead to an elevation of GAD mRNA per cell or an increase in the relative number of cells expressing GAD. However, our in situ hybridization data demonstrated that GAD67-expressing cells were widely spread outside the neuroepithelium throughout the cervical cord during embryogenesis, and became restricted to the dorsal horn region during postnatal development. A local decrease in the number of cells capable of expressing GAD mRNA could account for the postnatal decline in GAD transcript abundance observed with QRTPCR. This shift in localization was incorporated into the model to account for the postnatal kinetics.

Although the patterns of GAD65, GAD67, and EP10 gene expression followed qualitatively distinct time courses, this differences disappear when GAD67 and EP10 are combined into a pre-GAD67 transcript. Since GAD65 and GAD67 genes exhibit $70 \%$ sequence homology, it seems plausible that they share 
some common regulatory mechanisms. We assume that editing of pre-GAD67 is the source for differential expression of GAD67 and EP10. The alternative splicing ratio for EP10 mRNA, $R_{\text {EP10 }}$, underwent a double exponential decrease following a period of stability approaching 1 during early development. This was confirmed by the close fit of the measured experimental data to the empirical biexponential equation describing $R_{\mathrm{EP} 10}$.

A major advantage of mathematical modeling is the provision of an internally consistent, unambiguously formulated working hypothesis, serving as the basis for further experimental tests. This dialectic approach has been effective in the topical field of intracellular $\mathrm{Ca}^{2+}$ oscillations (reviewed in Stucki and Somogyi, 1994). Our model makes the following predictions. (1) GAD upregulates its own expression. Transgenic knockout experiments targeting GAD could corroborate this thesis, providing the data could be reproduced in a mouse model. By substituting the wild-type GAD65 or GAD67 gene with a sequence that codes for an enzymatically inactive GAD, GAD transcripts would remain detectable by PCR, but the proposed feedback mechanism depending on GABA production would be altered. The observed upregulation of GAD mRNA during prenatal development, which is dependent on GAD activity according to our model, should hence be curtailed. Furthermore, the roles of putative signaling components, such as GABA, GABA receptors, intracellular $\mathrm{Ca}^{2+}$, and other signal transduction pathways could be evaluated. Such experiments would most suitably be conducted using dissociated-cell or slice cultures of embryonic spinal cord. By manipulating $\mathrm{Ca}^{2+}$ using ionophores or chelators, adding GABA and GABA-related ligands, one could determine how these parameters affect the level of GAD family transcripts in an in vitro system. (2) Increased GAD gene transcription underlies the exponential embryonic phase. This may be tested in nuclear run-on transcription experiments. Cells from embryonic spinal cord could be dissociated enzymatically, broken up into their constituent organelles, and nuclei isolated using differential centrifugation. The rate of transcription could then be measured in vitro using run-on transcription protocols. (3) The steady-state level of GAD expression relies on increased mRNA degradation. Measurement of the half-life of GAD transcripts would provide an unequivocal test. This could be determined in vivo by pulsing animals with labeled ribonucleotide precursors and measuring the amount of labeled GAD transcripts after different time intervals using an assay based on hybridization to immobilized antisense probes. The decay of the labeled GAD signal would then be used to calculate the half-life.

\section{References}

Arnheim N (1992) Polymerase chain reaction strategy. Annu Rev Biochem 61:131-156.

Behar TN, Schaffner A, Laing P, Hudson L, Komoly S, Barker JL (1993a) Many spinal cord cells transiently express low molecular weight forms of glutamic acid decarboxylase during embryonic development. Dev Brain Res 72:203-218.

Behar TN, Schaffner AE, Colton CA, Somogyi R, Olah Z, Lehel C, Barker JL (1993b) GABA-induced chemokinesis and NGF-induced chemotaxis of embryonic spinal cord neurons. J Neurosci 13:29-38.

Bond RW, Wyborski RJ, Gottlieb DI (1990) Developmentally regulated expression of an exon containing a stop codon in the gene for glutamic acid decarboxylase. Proc Natl Acad Sci USA 87:8771-8775.

Chomczynski P, Sacchi N (1987) Single-step method of RNA isolation by acid guanidinium thiocyanate-phenol-chloroform extraction. Anal Biochem 162:156-159.

Chou Q, Russell M, Birch DE, Raymond J, Bloch W (1992) Prevention of pre-PCR mis-priming and primer dimerization improves low-copynumber amplifications. Nucleic Acids Res 20:1717-1723.
Erdö SL, Michler A, Wolff JR (1991) GABA accelerates excitotoxic cell death in cortical cultures: protection by blockers of GABA-gated chloride channels. Brain Res 542:254-258.

Erlander MG, Tobin AJ (1991) The structural and functional hetero geneity of glutamic acid decarboxylase, a review. Neurochem Res 16:215-226.

Erlander MG, Tillakaratne NJK, Feldblum S, Patel N, Tobin AJ (1991) Two genes encode distinct glutamate decarboxylases. Neuron 7:91100.

Foley KP, Leonard MW, Engel JD (1993) Quantitation of RNA using the polymerase chain reaction. Trends Genet 9:380-385.

Greif KF, Erlander MG, Tillakaratne NJK, Tobin AJ (1991) Postnatal expression of glutamate decarboxylase in developing rat cerebellum. Neurochem Res 16:235-242.

Greif KF, Tillakaratne NJK, Erlander MG, Feldblum S, Tobin AJ (1992) Transient increase in expression of a glutamate decarboxylase (GAD) mRNA during the postnatal development of the rat striatum. Dev Biol 153:158-164.

Hao R, Schmit JC (1993) Cloning of the gene for glutamate decarboxylase and its expression during conidiation in Neurospora crassa. Biochem J 293:735-738.

Holliday J, Adams RJ, Sejnowski TJ, Spitzer NC (1991) Calciuminduced release of calcium regulates differentiation of cultured spinal neurons. Neuron 7:787-796.

Jones MD, Foulkes NS (1989) Reverse transcription of mRNA by Thermus aquaticus DNA polymerase. Nucleic Acids Res 17:83878388.

Julien J-P, Ramachandran K, Grosveld F (1985) Cloning of a cDNA encoding the smallest neurofilament protein from the rat. Biochim Biophys Acta 825:398-404.

Kim HY, Sapp DW, Olsen RW, Tobin AJ (1993) GABA alters GABA receptor mRNAs and increases ligand binding. $J$ Neurochem 61: 2334-2337.

Lauder JM (1993) Neurotransmitters as growth regulatory signals, role of receptors and second messengers. Trends Neurosci 16:233-240.

Lauder JM, Han VKN, Henderson P, Verdoorn T, Towle AC (1986) Prenatal ontogeny of the GABAergic system in the rat brain, an immunocytochemical study. Neuroscience 19:465-493.

Lendahl U, Zimmerman LB, McKay RD (1990) CNS stem cells express a new class of intermediate filament protein. Cell 60:585 595 .

Liang P, Averboukh L, Pardee AB (1993) Distribution and cloning of eukaryotic mRNAs by means of differential display, refinements and optimization. Nucleic Acids Res 21:3269-3275.

Ma W, Behar T, Maric D, Maric I, Barker J (1992) Neuroepithelial cells in the rat spinal cord express glutamate decarboxylase immunoreactivity in vivo and in vitro. J Comp Neurol 325:257-270.

Ma W, Saunders P, Somogyi R, Poulter M, Barker J (1993) Ontogeny of $\mathrm{GABA}_{\mathrm{A}}$ receptor subunit mRNAs in rat spinal cord and dorsal root ganglia. J Comp Neurol 338:337-359.

Maric D, Maric I, Smith SV, Barker JL (1993) Attomolar GABA and GABA mimetics induce transient $\mathrm{Ca}_{i}{ }^{2+}$ release from ryanodine-sensitive stores in embryonic rat cerebral cortical cells. Soc Neurosci Abstr 19:274.13.

Michelsen BK, Peterson JS, Boel E, Moeldrup A, Dyrberg T, Madsen D (1991) Cloning, characterization and autoimmune recognition of rat islet glutamic acid decarboxylase in insulin-dependent diabetes melitus. Proc Natl Acad Sci USA 88:8754-8758.

Napolitano EW, Chin SS, Colman DR, Liem RK (1987) Complete amino acid sequence and in vitro expression of rat NF-M, the middle molecular weight neurofilament protein. J Neurosci 7:2590-2599.

Nixon RA, Shea TB (1992) Dynamics of neuronal intermediate filaments, a developmental perspective. Cell Motil Cytoskel 22:81-91.

Redburn DA, Schousboe A, eds (1987) Neurology and neurobiology, Vol 32, Neurotrophic activity of GABA during development. New York: Liss.

Reichling DB, Kyrozis A, Jian W, MacDermott AB (1994) Mechanisms of GABA and glycine depolarization-induced calcium transients in rat dorsal horn neurons. J Physiol (Lond) 476:411-422.

Rimvall K, Martin DL (1992) Increased intracellular $\gamma$-aminobutyric acid selectively lowers the level of the larger of two glutamate decarboxylase proteins in cultured GABAergic neurons from rat cerebral cortex. J Neurochem 58:158-166.

Rimvall K, Sheikh SN, Martin DL (1993) Effects of increased $\gamma$ - aminobutyric acid levels on GAD67 protein and mRNA levels in rat cerebral cortex. J Neurochem 60:714-720. 
Schaffner AE, Behar T, Nadi S, Barker JL (1993) Quantitative analysis of transient GABA expression in embryonic and early postnatal rat spinal cord neurons. Dev Brain Res 72:265-276.

Siebert PD, Larrick JW (1992) Competitive PCR. Nature 359:557-558.

Sivilotti L, Nistri A (1991) GABA receptor mechanisms in the central nervous system. Prog Neurobiol 36:35-92.

Spitzer NC (1991) A developmental handshake, neuronal control of ionic currents and their control of neuronal differentiation. J Neurobiol 22:659-673.

Spitzer NC, Debaca RC, Allen KA, Holliday J (1993) Calcium dependence of differentiation of GABA immunoreactivity in spinal neurons. J Comp Neurol 337:168-175.

Spoerri PE (1988) Neurotrophic effects of GABA in cultures of embryonic chick brain and retina. Synapse 2:11-22.

Stucki JW, Somogyi R (1994) A dialogue on $\mathrm{Ca}^{2+}$ oscillations: an attempt to understand the essentials of mechanisms leading to hormonc-induccd intraccllular $\mathrm{Ca}^{2+}$ oscillations in various kinds of cells on a theoretical level. Biochim Biophys Acta 1183:453-472.

Szabo G, Katarova Z, Greenspan R (1994) Distinct protein forms are produced from alternatively spliced bicistronic GAD mRNAs during development. Mol Cell Biol 14:7535-7545.

Tajima Y, Salvaterra PM (1992) Positive and negative feedback regulation of choline acetyltransferase mRNA levels in Drosophila: a study using temperature-sensitive mutants and embryo cell cultures. Brain Res 13:213-221.

Tse WT, Forget BG (1990) Reverse transcription and direct amplification of cellular RNA transcripts by Taq polymerase. Gene 88:293296.

Valeyev AY, Cruciani RA, Lange GD, Smallwood VS, Barker JL (1993) $\mathrm{Cl}^{-}$channels are randomly activated by continuous GABA secretion in cultured embryonic rat hippocampal neurons. Neurosci Lett 155:199-203.

Walton MK, Schaffner AE, Barker JL (1993) Sodium channels, GA$\mathrm{BA}_{\mathrm{A}}$ receptors, and glutamate receptors develop sequentially on embryonic rat spinal cord cells. J Neurosci 13:2068-2084.

Willcutts MD, Morrison-Bogorad M (1991) Quantitative in situ hybridization analysis of glutamic acid decarboxylase messenger RNA in developing rat cerebellum. Dev Brain Res 63:253-264.

Wu WL, Ziskind-Conhaim L, Sweet MA (1992) Early development of glycine-/and GABA-mediated synapses in rat spinal cord. J Neurosci 12:3935-3945.

Yoshizumi M, Perella MA, Burnett JC, Lee ME (1993) Tumor necrosis factor downregulates an endothelial nitric oxide synthase mRNA by shortening its half-life. Circ Res 73:205-209.

Zoja C, Bettoni S, Morigi M, Remuzzi G, Rambaldi A (1992) Interleukin-1 regulates cytokine gene expression in human mesangial cells through the interleukin-1 receptor type 1. J Am Soc Nephrol 2:1709_ 17015 . 